\title{
Pedestrian wind comfort near a super-tall building with various configurations in an urban-like setting
}

\author{
Xinyue Zhang', Asiri Umenga Weerasuriya ${ }^{2,3}(\varangle)$ Xuelin Zhang ${ }^{4}$, Kam Tim Tse ${ }^{2}$, Bin Lu', Cruz Yutong Li ${ }^{2}$, \\ Chun-Ho Liu ${ }^{3}$ \\ 1. Department of Architectural and Civil Engineering, City University of Hong Kong, Tat Chee Ave, Kowloon Tong, Hong Kong, China \\ 2. Department of Civil and Environmental Engineering, The Hong Kong University of Science and Technology, Clear Water Bay, Kowloon, \\ Hong Kong, China \\ 3. Department of Mechanical Engineering, The University of Hong Kong, Pokfulam, Hong Kong, China \\ 4. School of Atmospheric Sciences, Sun Yat-sen University, Guangzhou, China
}

\section{Abstract}

Pedestrian wind comfort near a $400 \mathrm{~m}$ super-tall building in high and low ambient wind speeds, referred to as Windy and Calm climates, is evaluated by conducting computational fluid dynamics (CFD) simulations. The super-tall building has 15 different configurations and is located the center of $50 \mathrm{~m}$ medium-rise buildings in an urban-like setting. Pedestrian level mean wind speeds near the super-tall building is obtained from three-dimensional (3D), steady-state, Reynolds-Averaged Navier-Stokes (RANS)-based simulations for five incident wind directions $\left(\theta=0^{\circ}, 22.5^{\circ}, 45^{\circ}, 90^{\circ}\right.$, $\left.180^{\circ}\right)$ that are subsequently compared with two wind comfort criteria specified for Calm and Windy climates. Results show a 1.53 times increase in maximum mean wind speed in the urban area after the construction of a square-shaped super-tall building. The escalated mean wind speeds result in a $23 \%-15 \%$ and $36 \%-29 \%$ decrease in the area with "acceptable wind comfort" in Calm and Windy climates, respectively. The area with pedestrian wind comfort varies significantly with building configuration and incident wind direction, for example, the configurations with sharp corners, large plan aspect ratios and, frontal areas and the orientation consistently show a strong dependency on incident wind direction except for the one with rounded plan shapes. Minor aerodynamic modifications such as corner modifications and aerodynamically-shaped configurations such as tapered and setback buildings show promise in improving pedestrian wind comfort in Windy climate.
\end{abstract}

\section{Introduction}

Since the beginning of the construction of tall buildings in cities, there was a public outcry about unpleasant and dangerous high-speed wind found near the base of tall buildings. Many of such incidents were recorded in countries including the United States (Durgin 1992), the United Kingdom (Penwarden and Wisse 1975; Lee and Hussain 1979), Canada (Isyumov 1978), Japan (Kamei and Maruta 1979; Murakami et al. 1979; Murakami et al. 1986), Australia (Melbourne 1978a), and France (Gandemer 1978a). The strong wind flows found near tall buildings are the results

\section{Keywords}

pedestrian wind comfort, super-tall building, building configuration, urban wind environment, computational fluid dynamics simulation

\section{Article History}

Received: 14 January 2020

Revised: 10 April 2020

Accepted: 30 April 2020

(c) Tsinghua University Press and Springer-Verlag GmbH Germany, part of Springer Nature 2020

E-mail: auw@connect.ust.hk

of intense downwash, which brings high-speed winds from higher altitudes down to the ground level and strong separation layers formed at the sharp corners of tall buildings (Beranek 1984). When windy areas became a perilous environmental issue in cities, researchers invented techniques to assess wind environment near tall buildings (Irwin 1981; Beranek 1984; Uematsu and Yamada 1991; Wu and Stathopoulos 1993) and developed evaluation criteria to estimate wind comfort of pedestrians in built-up areas (Jackson 1978; Melbourne 1978b; Hunt et al. 1976; Durgin 1997). City authorities had also attempted to regulate the occurrence of adverse wind flows in built-up areas by stipulating wind 
ordinances and building design guidelines (Arnes et al. 1989; Durgin 1989; Willemsen and Wisse 2007; Ng 2009).

Although the occurrence of high-speed winds is a common issue associated with the construction of tall buildings, ironically, over the last few decades, pedestrian-level wind nuisance in cities such as Hong Kong, Milan, Delhi, and Tokyo, where many tall buildings have been constructed, has transformed from unpleasant high-speed winds to undesirable low-speed winds. The undesirable low-speed winds are a combined effect of low ambient wind speed and poor urban planning such as closely spaced tall buildings, bulky podium structures, deep street canyons, and many more (Ng 2009; Yim et al. 2009; Tsang et al. 2012). Several wind-related environmental issues in cities such as accumulation of vehicular emission at street level (Wang et al. 2001), degradation of outdoor thermal comfort (Cheng et al. 2012), exaggeration of urban heat island (UHI) effect (Wong et al. 2010), and quick spreading of airborne pathogens (Yip et al. 2007) arise from low wind speed and subsequently cause deteriorating the urban quality of life. In such context, an increase of wind circulation near ground level - as it deems to occur with the construction of tall buildings - would be beneficial for cities suffering from low wind speeds. However, extra precautions should be taken in designing tall buildings even in cities with low ambient wind speeds to ensure that the intentional increase of ground-level wind speed is of benefit instead of peril for pedestrians. Nowadays, maintaining acceptable wind conditions in built-up areas becomes increasingly difficult because modern tall buildings with unconventional shapes produce extremely complex flow fields, which are difficult to predict using conventional knowledge of wind engineering.

Compared with the well-known positive correlation between building height and maximum wind speed near tall buildings (Stathopoulos et al. 1992; Tsang et al. 2012; Tse et al. 2017a), the relation between tall buildings with unconventional configurations and pedestrian-level wind speed is not well understood. Here, unconventional configurations refer to building designs that considerably deviate from traditional building shapes such as square, rectangular, circular, and elliptical. Unconventional configurations have emerged as an effective aerodynamic treatment for tall buildings to mitigate excessive wind-induced building responses, particular those of tall buildings with great heights and high slenderness (i.e., the ratio between height and width of the building) (Kwok 1988; Dutton and Isyumov 1990; Kawai 1998; Kim and Jun 2010; Tamura et al. 2010; Kim et al. 2014, 2015a, 2015b; Tanaka et al. 2012, 2013; Tse et al. 2009). Tall buildings with even minor aerodynamic treatments such as corner modifications show promise in suppressing aeroelastic instabilities, thereby minimizing wind-induced responses of tall buildings (Kawai 1998), and in reducing building construction cost (Tse et al. 2009). In addition to better aerodynamic performance, unconventional configurations are often adopted for tall buildings to design aesthetically superior buildings that stand out from the others.

However, as much as the available details on how unconventional configurations are advantageous in minimizing wind-induced building responses, little evidence is available for understanding how super-tall buildings with unconventional configurations modify wind fields near the ground. One of the evidence is provided by Xu et al. (2017) using the data of wind tunnel tests. They have tested scaledown models of a $400 \mathrm{~m}$ height building, which they have referred to as a super-tall building, with 40 different conventional and unconventional configurations. One of their observations is that the wind speed near the super-tall building more than doubles the ambient wind speed, and consequently, pedestrians near the super-tall building experience twice as large wind force compared to what they experience near a $200 \mathrm{~m}$ tall building. Moreover, their study has indicated that certain unconventional configurations such as circular, polygonal, and helical configurations, as well as corner modifications adopted for a super-tall building, can alleviate the occurrence of high-speed winds at the pedestrian level. Zhang et al. (2020) have simulated a super-tall building with many unconventional configurations in a regular urban area using computational fluid dynamics (CFD) simulations and provided valuable insights on how a super-tall building can influence pedestrian-level wind environment (PLWE) in built-up areas. They have found significant influences of the surrounding buildings on the PLWE near a super-tall building, for instance, maximum wind speed near a super-tall building in a regular urban area is smaller than its counterpart of an isolated super-tall building. Furthermore, Zhang et al. (2020) have recommended different unconventional configurations for a super-tall building to control pedestrian-level wind speed, for instance, building openings at a high level is suitable to provide maximum wind shelter for pedestrians while building openings at a lower height facilitates better wind circulation at the pedestrian level. Although a certain increase in pedestrian level wind speed near a super-tall building is shown in these two studies, they do not supply conclusive evidence whether the escalated wind speeds may cause pedestrian wind comfort, discomfort, or wind-related dangers. Therefore, the current study aims to shed light on this research problem by investigating pedestrian wind comfort near a super-tall building with various configurations in a regular urban area using CFD simulation.

CFD simulation has emerged as a feasible substitute for conventional wind tunnel experiments by virtue of the rapid increase of computational power and improved turbulence 
modeling. In particular, three-dimensional (3D), steady-state, Reynolds-Averaged Navier Stokes (3D RANS) equations based CFD simulation has become a popular tool for modeling PLWE and evaluating pedestrian wind comfort in built-up areas (Stathopoulos and Wu 2004; Tominaga et al. 2004; Yoshie et al. 2007; Mochida and Lun 2008; Blocken and Person 2009; Janssen et al. 2013). The popularity of 3D RANS simulation mainly resorts on its ability to simulate mean wind field faster and accurately, which are two essential features for evaluating PLWE using pedestrian-level mean wind speed (Stathopoulos and $\mathrm{Wu}$ 2004; Blocken and Stathopoulos 2013; Blocken et al. 2016). Moreover, the use of 3D RANS simulations for PLWE studies is currently well established by abundantly available literature and further strengthened by the availability of best practice guidelines. However, 3D RANS has a few inherent shortcomings in modeling wind field because of the use of two-equation turbulence closure models such as the $k-\varepsilon$ turbulence models. It is a well-known fact that the $k$ - $\varepsilon$ turbulence models overestimate turbulent kinetic energy (TKE) at the stagnation point near the frontal building corner, underestimates TKE in recirculation regions predicting smaller separation and recirculation regions on the roof and sidewalls, and larger building wakes (Blocken 2018). Most of these shortcomings can be avoided by using large eddy simulation (LES). However, the lack of best practice guidelines, the complexity in simulation setup, and the need for running many simulations for PLWE studies make LES unfeasible as a tool for assessing PLWE in urban areas (Yoshie et al. 2007; Blocken 2014, 2018). Therefore, this study chooses 3D RANS over LES as the CFD simulation technique, while acknowledging the inherent shortcomings of the selected technique.

The objective of this study is four-fold: (1) to investigate how the PLWE in a regular urban area changed after the construction of a super-tall building; (2) to estimate how the modified PLWEs affect pedestrian wind comfort in two diametrically different wind climates with high and low ambient wind speeds; (3) to explore how pedestrian wind comfort in the two wind climates varies with various configurations of a super-tall building; and (4) to develop a set of guidelines for designers to select suitable configurations for super-tall buildings located in the two wind climates. The details of the super-tall building, the selected building configurations, and the regular urban area are presented in Section 2. Section 3 introduces wind conditions in two diametrically different wind climates and wind comfort criteria used for this study. Section 4 introduces the CFD simulation technique and describes the grid discretization method, boundary conditions, and solver settings of the simulations. The accuracy of CFD simulation is estimated in Section 5 by conducting a grid sensitivity analysis and a validation test. Section 6 presents the assessment of pedestrian wind comfort near the super-tall building with various configurations in the two wind climates. Some of the limitations of the study are reported in Section 7, and concluding remarks are drawn in Section 8.

\section{Details of the super-tall building designs}

A tall building with the dimensions of $400 \mathrm{~m} \times 50 \mathrm{~m} \times 50 \mathrm{~m}$ (height $(H) \times$ width $(W) \times$ depth $(D))$ and a constant volume of $1 \times 10^{6} \mathrm{~m}^{3}$ was chosen as the super-tall building for the current study. The super-tall building had 15 different conventional and unconventional configurations (Figure 1). Five conventional configurations, including square, rectangular, circular, elliptical and triangular are categorized as "Basic shapes", while the rest of configurations are considered to be as unconventional. Unconventional configurations consist of "Corner modifications" - chamfered and cut; "Openings" top opening and lift-up; "Polygonal" - pentagonal and octagonal; "Tapered" - a two-side tapered, setback, and "Varying cross-section and orientation" - setback with $45^{\circ}$ rotation; and "Tilted". These configurations were selected based on several previous studies (Tamura et al. 2010; Tanaka et al. 2012, 2013; Xu et al. 2017; Zhang et al. 2020) that physically and numerically modeled super-tall buildings.

The regular urban area - where the super-tall building is located - consists of 25 medium-rise buildings with the dimensions of $50 \mathrm{~m} \times 50 \mathrm{~m} \times 50 \mathrm{~m}$ (SQB in Figure 1). These buildings are arranged in a $5 \times 5$ array with $50 \mathrm{~m}$ wide streets running along longitudinal and lateral wind directions. This particular urban form can be considered as to be representative of a medium-dense urban area as it has a frontal area index $\left(\lambda_{\mathrm{f}}\right.$, ratio between the frontal area and ground surface area) of 0.25 , plan area index $\left(\lambda_{\mathrm{p}}\right.$, ratio between the building plan area and ground surface area) of 0.25 , and a street aspect ratio ( $S R$, ratio between building height and street width) of 1 (Grimmond and Oke 1999). The medium-dense urban area is the most common building layout used for physical and numerical simulation of urban wind environments (Lin et al. 2014).

\section{Wind climates and wind comfort criteria}

Two wind climates, namely Calm and Windy climates, were selected for this study to assess pedestrian wind comfort near a super-tall building in a regular urban area. Here Calm and Windy climates are specified based on relatively low or high ambient wind speed in the two climates, respectively. The selection of two wind climates is motivated by two factors; first, pedestrian level wind speed in built-up areas depends on ambient wind speed. Therefore, there is a high probability that a pedestrian is exposed to high-speed wind flows near a super-tall building in Windy climate 


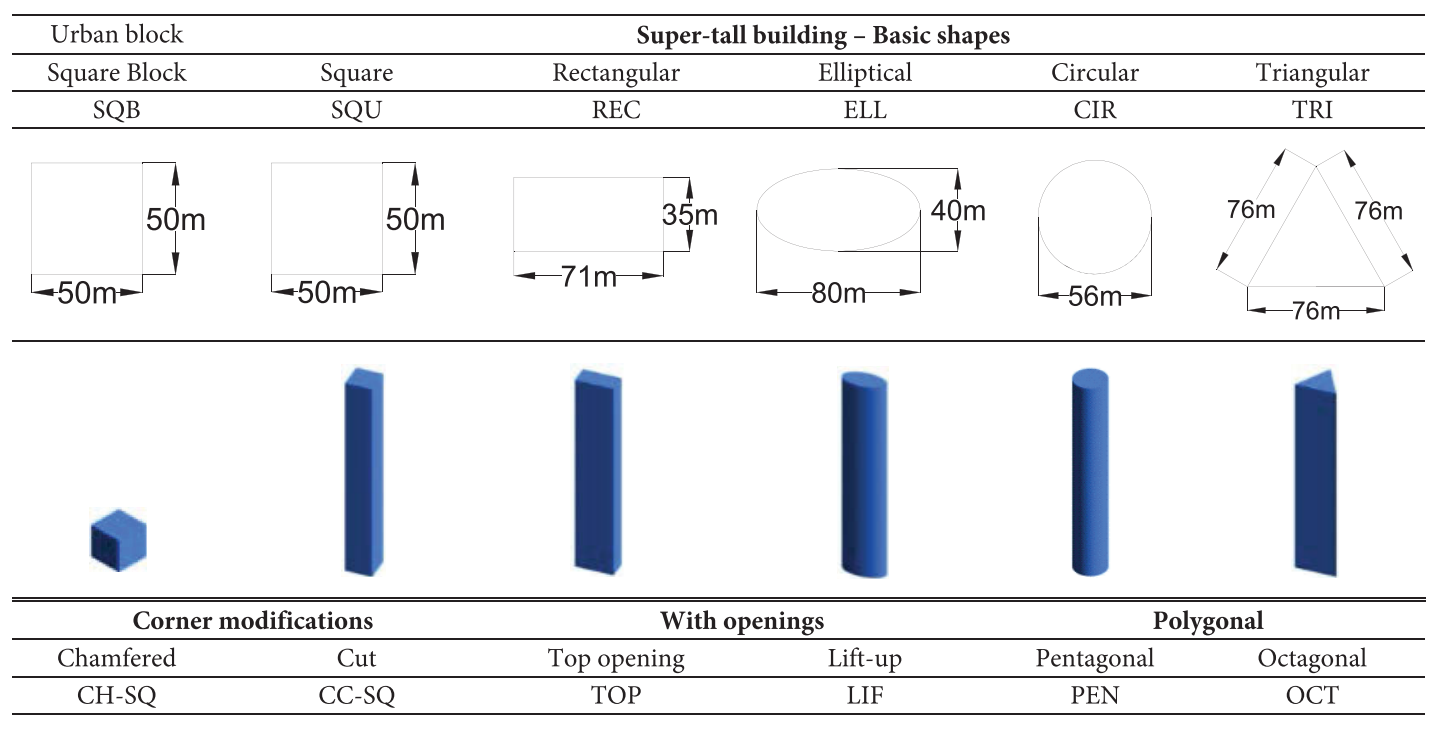
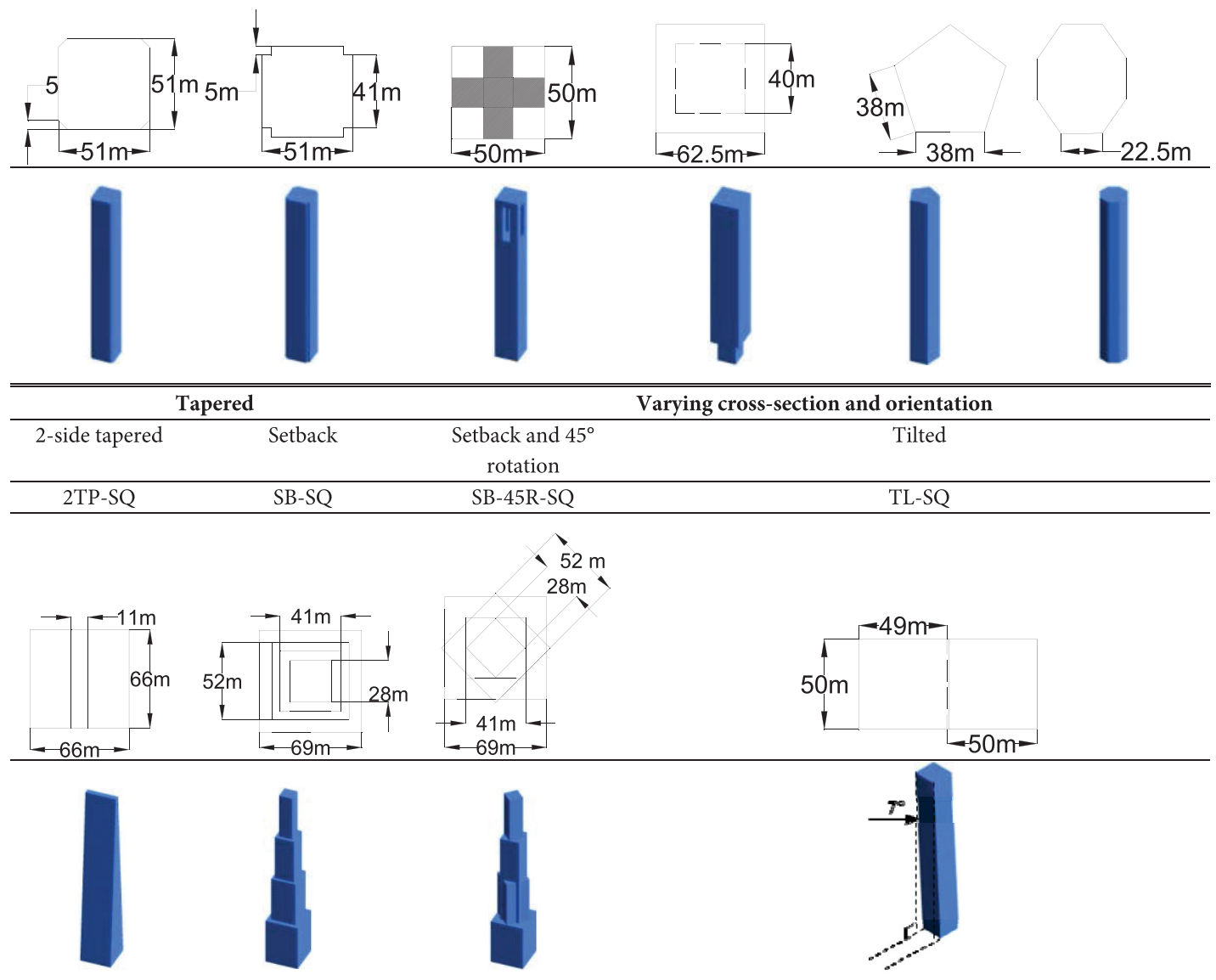

Fig. 1 Conventional and unconventional configurations used for a super-tall building

compared to a person walking near a similar super-tall building in Calm climate. Second, some configurations selected for this study are considered to be as unfit for buildings in Windy climate, while the same configurations are preferred in Calm climate. An example is the "lift-up" design (LIF in Figure 1), which is found to be advantageous in improving wind circulation at pedestrian level in low ambient wind speeds (Tse et al. 2017b; Zhang et al. 2017, 2018), while another set of studies predicts the occurrence of adverse wind conditions near lift-up buildings in windy environments (Penwarden and Wisse 1975; Beranek 1984; Stathopoulos et al. 1992; Gandemer 1978b; Melbourne 1971). 
The average wind conditions in Hong Kong and Montreal were selected as representative of Calm and Windy climates, respectively (Figure 2). The wind conditions in Calm climate is described by a power-law type mean wind profile with an exponent of 0.15 and the reference mean wind speed of $6.83 \mathrm{~ms}^{-1}$ at $200 \mathrm{~m}$ height. Windy climate has a high mean wind speed of $4 \mathrm{~ms}^{-1}$ at a reference height of $10 \mathrm{~m}$ in a powerlaw type wind profile with an exponent of 0.16 . Although it is common to estimate wind comfort using wind statistics in each wind direction, this study adopts wind statistics weighted averaged over 16 wind directions for the wind comfort calculation. This approach is prefered because of the current study focuses on assessing the impacts of super-tall buildings on pedestrian wind comfort rather than estimating the influence of approaching wind conditions. By using the averaged wind statistics, this study can eliminate the differential impacts of wind statistics in 16 directions on the calculation and can highlight only the influence of a super-tall building on its surrounding. It is noted that these two wind profiles are different from the profile of mean wind speed used for the CFD simulation (see Section 4) thus the wind speeds are needed to be transfred from CFD simulation to the two wind climates as proposed by Gandemer (1978b), Blocken and Parsoon (2009), and Zhang et al. (2017).

The wind speed conversion is started by defining normalized mean wind speed ratio, as expressed in Equation (1).

$K=\left(\frac{U_{2 \mathrm{~m}}}{U_{2 \mathrm{~m}, \text { ambient,CFD }}}\right)$

Here, $U_{2 \mathrm{~m}}$ and $U_{2 \mathrm{~m}}$, ambient are the pedestrian-level ( $2 \mathrm{~m}$ height in full scale) mean wind speeds in the presence and absence of buildings in the CFD simulation, respectively.

The pedestrian-level wind speed in CFD simulation is transferred to the corresponding wind speed in a wind

(a)

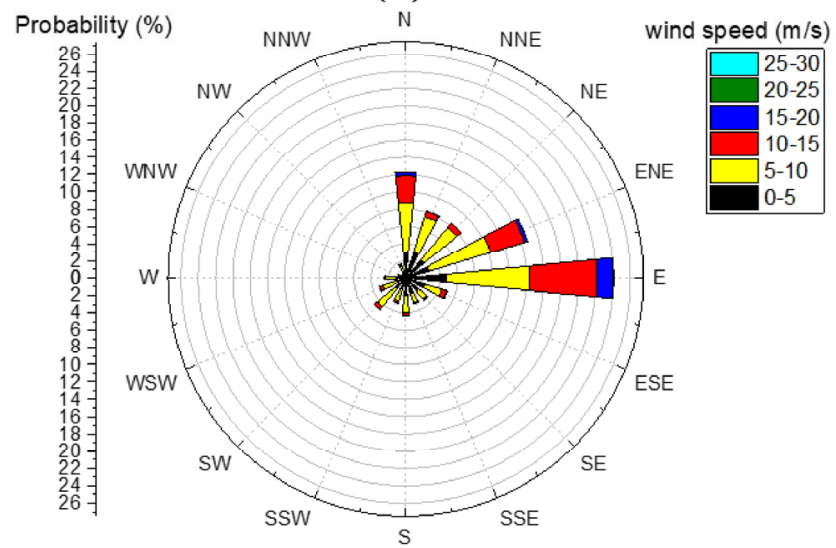

climate following the procedure shown in Equation (2).

$$
\left.\begin{array}{l}
K^{\prime}=\left(\frac{U_{2 \mathrm{~m}}}{U_{\text {ref, } \mathrm{WC}}}\right) \\
K^{\prime}=\left(\frac{U_{2 \mathrm{~m}}}{U_{2 \mathrm{~m}, \mathrm{mmbient}, \mathrm{CFD}}}\right)_{\alpha_{\mathrm{CPD}}} \cdot\left(\frac{U_{2 \mathrm{~m}}}{U_{\text {ref }}}\right)_{\alpha_{\mathrm{WC}}} \\
K^{\prime}=\left(\frac{U_{2 \mathrm{~m}}}{U_{2 \mathrm{~m}, \mathrm{ambient}, \mathrm{CFD}}}\right)_{\alpha_{\mathrm{CFD}}} \cdot \frac{U_{\mathrm{G}}\left(\frac{2}{z_{\mathrm{G}}}\right)^{\alpha_{\mathrm{WC}}}}{U_{\mathrm{G}}\left(\frac{z_{\text {ref }}}{z_{\mathrm{G}}}\right)^{\alpha_{\mathrm{WC}}}} \\
K^{\prime}=\left(\frac{U_{2 \mathrm{~m}}}{U_{2 \mathrm{~m}, \mathrm{ambient}, \mathrm{CFD}}}\right)_{\alpha_{\mathrm{CPD}}} \cdot\left(\frac{2}{z_{\text {ref }}}\right)^{\alpha_{\mathrm{WC}}} \\
K^{\prime}=K \times C \\
U_{2 \mathrm{~m}, \mathrm{WC}}=K^{\prime} \times U_{\text {ref,WC}}=K \times C \times U_{\text {ref }, \mathrm{WC}}
\end{array}\right\}
$$

where $K^{\prime}$ is normalized mean wind speed ratio in the relevant wind climate (WC) calculated by mean wind speed at the pedestrian level $\left(U_{2 \mathrm{~m}}\right)$ and the referene mean wind speed $\left(U_{\text {ref,WC }}\right)$ at the reference height $z_{\text {ref, }}, \alpha_{\mathrm{CFD}}$ is the power-law exponent of the wind profile used for CFD simulation; $\alpha_{\mathrm{WC}}$ is the power-law exponent of the wind profile in the wind climate; $U_{\mathrm{G}}$ is the gradient wind speed in the wind climate; $z_{\mathrm{G}}$ is gradient height, $C$ is a conversion factor for a particular wind climate equal to $\left(2 / z_{\text {ref }}\right)^{\alpha_{\mathrm{WC}}}$.

The converted wind speeds were subsequently employed to assess pedestrian wind comfort near a super-tall building in a wind climate using a wind comfort criterion (Table 1). The criteria proposed by Du et al. (2017) and Lawson (1978) evaluate pedestrian wind comfort in Calm and Windy climates, respectively. Du et al. (2017) have assumed an acceptable wind environment if it is suitable for activities: "Sitting long", "Sitting short", and "Strolling". This analogy tallies with Lawson's criteria thus, the current study adopts the same definition to estimate the area with wind comfort $\left(A_{\text {com }}\right)$ in both Calm and Windy climates.

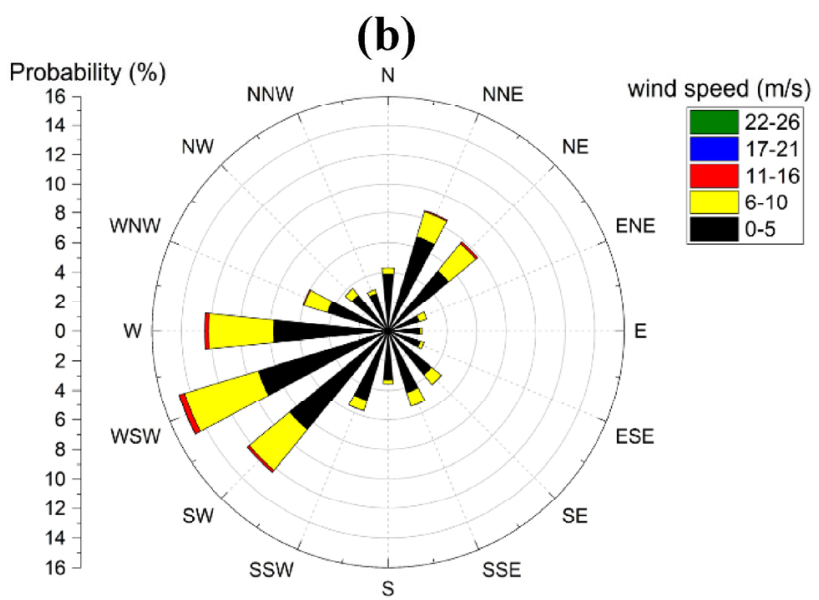

Fig. 2 Wind climate model of (a) Hong Kong (Weerasuriya et al. 2018), and (b) Montreal (Wu 1994) 
Table 1 Two wind comfort criteria for Calm and Windy climates

\begin{tabular}{cccc}
\hline $\begin{array}{c}\text { Comfort } \\
\text { class }\end{array}$ & $\begin{array}{c}\text { Threshold wind } \\
\text { speed }\left(\mathrm{ms}^{-1}\right)\end{array}$ & $\begin{array}{c}\text { Exceedance } \\
\text { probability }\end{array}$ & $\begin{array}{c}\text { Activity } \\
\text { description }\end{array}$ \\
\hline Calm climate (Du et al. 2017) \\
\hline Unfavorable & $<1.5$ & $50 \%$ & N/A \\
\hline Acceptable & $<1.8$ & $2 \%$ & Sitting long \\
& $<3.6$ & $2 \%$ & Sitting short \\
& $<5.3$ & $2 \%$ & Strolling \\
\hline Tolerable & $<7.6$ & $2 \%$ & Walking fast \\
Intolerable & $>7.6$ & $2 \%$ & Not suitable for \\
& $>15$ & $0.05 \%$ & activities \\
Danger & \multicolumn{2}{c}{ Windy climate (Lawson 1978) } \\
\hline \hline & $\leq 1.8$ & $2 \%$ & Sitting long \\
\hline Acceptable & $\leq 3.6$ & $2 \%$ & Sitting short \\
& $\leq 5.3$ & $2 \%$ & Strolling \\
\hline Tolerable & $\leq 7.6$ & $2 \%$ & Walking fast \\
Intolerable & $>7.6$ & $2 \%$ & Not suitable for \\
& & & activities \\
\hline
\end{tabular}

\section{CFD simulations: computational settings and parameters}

\subsection{Computational domain and mesh generation}

The computational domain used for this study contains a super-tall building and a group of medium-rise buildings (Figure 3). Similar to the building models used for the wind tunnel test by Xu et al. (2017) and the CFD simulation by Zhang et al. (2020), all buildings were modeled in a reduced scale of 1:500. The inlet was set $3 H$ upstream from the windward edge of the building cluster to prevent unintended streamwise gradients in the wind profile from developing (Blocken et al. 2007a, b). The lateral and top boundaries

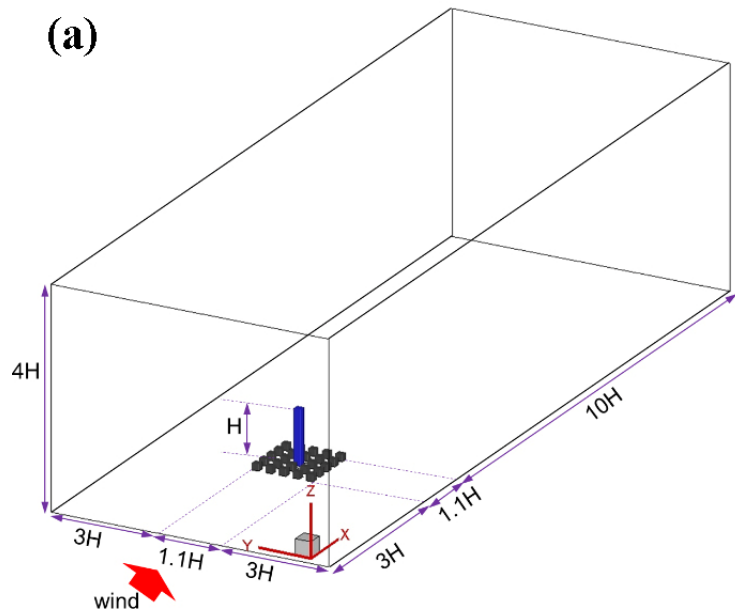

were located at $3 \mathrm{H}$ away from the side edges of the building group and the top of the super-tall building, respectively. This setup results in a blockage ratio of $0.5 \%$, which duly satisfies the maximum allowable blockage ratio of $3 \%$ recommended by the best practice guidelines (Tominaga et al. 2008; Franke et al. 2011). The outlet was at a distance of $10 \mathrm{H}$ downstream of the building group to ensure an adequate downstream fetch for the wind to recover.

A high-quality mesh was created using the surface-grid extrusion technique proposed by van Hooff and Blocken (2010), as shown in Figure 3(b). A surface mesh with controlled grid dimensions was first created before being extruded in the perpendicular direction to the surface mesh for maximum control over the grid topology. This technique ensures that all cells in the computational domain are hexahedral, and the height of the first cell above the ground $\left(y_{\mathrm{H}}\right)$ is larger than twice the sand-grain roughness $\left(k_{\mathrm{s}}\right)-$ two essential conditions for an accurate CFD simulation (Tominaga et al. 2008; Janssen et al. 2013; Ramponi et al. 2015).

\subsection{Boundary conditions}

Figure 4 shows three profiles of mean wind speed $(U)$, TKE $(k)$, and TKE dissipation rate $(\varepsilon)$ used as the boundary conditions at the inlet of the computational domain. The profiles of $U$ and $k$ are adopted from the study of Yoshie et al. (2007), and the $\varepsilon$ profile is derived by:

$\varepsilon=\frac{\left(u_{\mathrm{ABL}}^{*}\right)^{3}}{\kappa\left(z+z_{\mathrm{o}}\right)}$

where $u_{\mathrm{ABL}}^{*}\left(=0.499 \mathrm{~ms}^{-1}\right)$ is the frictional velocity, $z$ is the height above the ground, $z_{\mathrm{o}}(=0.00053 \mathrm{~m})$ is the roughness length that equals, and $\kappa(=0.42)$ is the von Karman constant.

Various boundary conditions were applied to the boundaries of the computation domain; Outlet was assigned

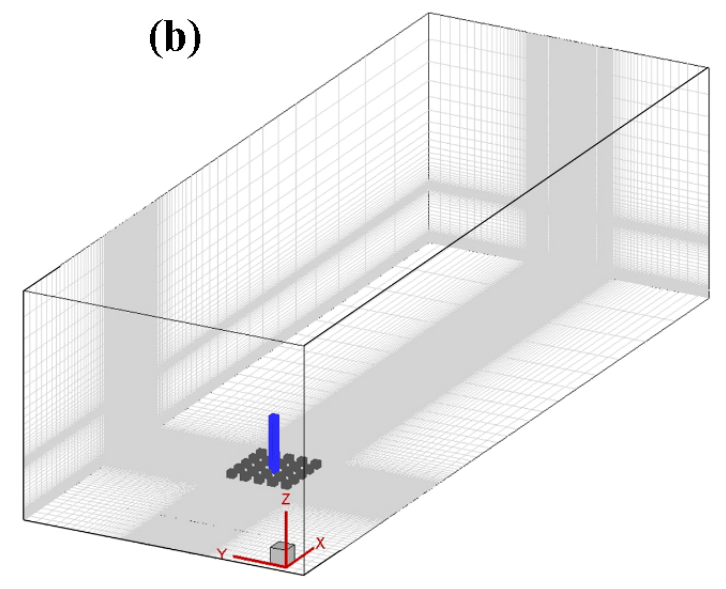

Fig. 3 (a) Dimensions of the computational domain, (b) perspective view of the computational grid 

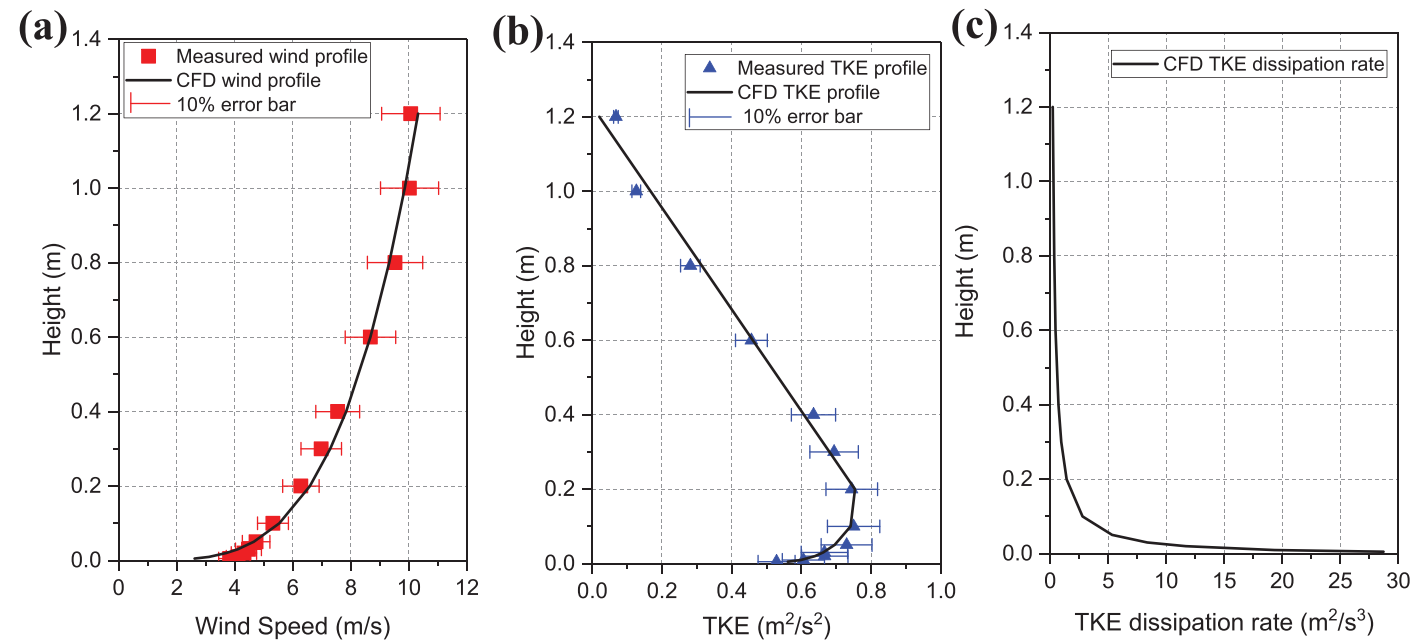

Fig. 4 Vertical profiles of (a) mean wind speed $(U),(b)$ TKE $(k)$, and (c) TKE dissipation rate $(\varepsilon)$

with Outflow boundary condition, where $\partial(u, v, w, k, \varepsilon) /$ $\partial x=\partial(u, v, w, k, \varepsilon) / \partial y=0$. Symmetry boundary condition that assumed zero normal velocity and gradient across surfaces was applied to Lateral and Top boundaries. The building surfaces were considered to be smooth, while Ground was modeled as a rough wall using the standard wall function (Launder and Spalding 1983) and the sand-grain roughness (Cebeci and Bradshaw 1977). The sand-grain roughness $\left(k_{s}\right)$ is calculated using the relationship $k_{\mathrm{s}}=9.793 z_{\mathrm{o}} / C_{\mathrm{s}}$ with a sand roughness constant $\left(C_{\mathrm{s}}\right)$ of 7 .

\subsection{Solver settings and other parameters}

ANSYS Fluent v19.2 - a popular commercial software package - was used to perform 3D RANS-based CFD simulation. The realizable $k-\varepsilon$ model (Shih et al. 1995) was selected as the two-equation turbulence closure for the CFD simulation due to its superior performance in modeling the mean flow of complex structures, flows involving rotation, boundary layers under strong adverse pressure gradients, and flow separation and recirculation (Davis et al. 2012).
The semi-implicit method for pressure linked equations (SIMPLE) algorithm was used for pressure-velocity coupling, and the pressure interpolation was of second-order accuracy. The convection and viscous terms in the governing equations were solved using second-order discretization schemes. The results of the CFD simulations were considered to have converged when the residuals of iteration had reached these values: continuity $-10^{-6}, x-, y$-, $z$-momentum $-10^{-7}, k-10^{-7}$, and $\varepsilon-10^{-7}$, and showed no further reduction as the number of iterations increased.

\section{Accuracy of CFD simulation}

\subsection{Grid sensitivity analysis}

Figure 5 shows three grids, namely Coarse, Intermediate, and Fine grids prepared for SQU in the regular urban area case for the grid-sensitivity analysis. The three grids employ a grid coarsening/refining factor $\sqrt{2}$ to divide the road width into 8 cells (Coarse), 12 cells (Intermediate), and 16 cells (Fine). The grid-sensitivity of CFD simulation is estimated
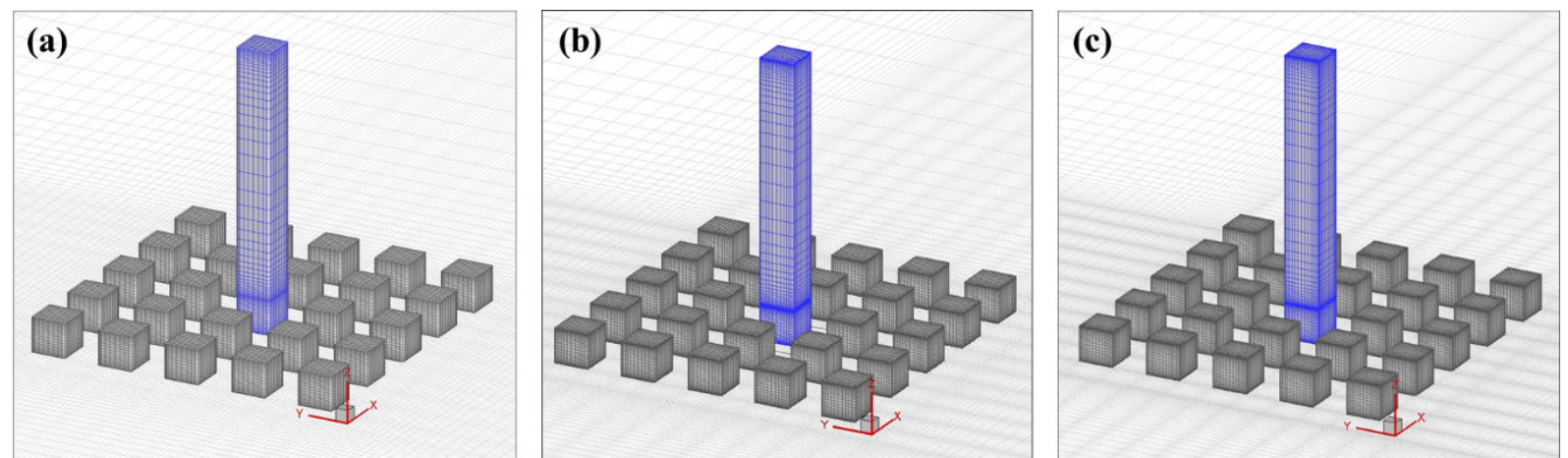

Fig. 5 Geometries for grid-sensitivity analysis: (a) Coarse grid: 2,135,936 cells, (b) Intermediate grid: 4,575,444 cells, and (c) Fine grid: $7,083,008$ cells 
by the root-mean-square-error (RSME) (Equation (4)) of $K$ value (Equation (1)) at many grid points as shown in Figure 6(a).

$$
\mathrm{RSME}=\sqrt{\frac{1}{n} \sum_{i=1}^{n}\left(K_{1, i}-K_{2, i}\right)^{2}}
$$

where $K_{1, i}$ and $K_{2, i}$ are normalized mean wind speed ratio at the same locations in grid 1 and 2.

Figure 6 shows the comparison of $K$ value between Coarse-Intermediate, Coarse-Fine, and Intermediate-Fine grids. The deviation of Coarse and Intermediate grids is more than $20 \%$, in particular, if $K$ is less than 1 , and that results in RMSE of 0.0393 (Figure 6(b)). A similar deviation in $K$ and RMSE value (0.0384) can be observed in Figure 6(c) by comparing results of Fine and Coarse grids. Conversely, the results of Intermediate and Fine grids are similar and have less than $10 \%$ of discrepancies over a wide range of $K$ value (Figure $6(\mathrm{~d})$ ). A smaller RSME $(=0.0029)$ of the comparison between Intermediate-Fine grids is indicative of less deviation of the magnitude of wind speed in the two meshes thus the grid independence results. By considering the accuracy and computational cost, Intermediate grid was selected for the rest of the CFD simulations in this study.

\subsection{Validation test}

A validation test was performed to estimate the accuracy of the CFD simulation technique used in this study. The validation data set contains the pedestrian-level wind speed measured in a regular urban area in a wind tunnel test published by the Architectural Institute of Japan (AIJ n.d.). The urban area consists of a tall building with the full-scale dimensions: $H(=100 \mathrm{~m}) \times W(=25 \mathrm{~m}) \times D(=25 \mathrm{~m})$ and a group of low-rise buildings with the dimensions: $h(=10 \mathrm{~m}) \times$ $w(=25 \mathrm{~m}) \times d(=25 \mathrm{~m})$ and $20 \mathrm{~m}$ and $30 \mathrm{~m}$ wide streets. Yoshie et al. (2007) used the same data set to validate a series of CFD simulations and concluded neither the number of surrounding blocks nor the turbulence closure model had an impact on the CFD simulation results. Therefore, this study modeled a $5 \times 5$ matrix of urban blocks and used the realizable $k-\varepsilon$ model as the turbulence closure. The computational grid was created using the surface-grid extrusion technique with 1,089,336 hexahedral cells, and the height of the first cell is $1.05 \mathrm{~mm}$ (in a 1:400 model scale) (Figure 7(a)). The inlet boundary conditions were provided as $U, k$, and $\varepsilon$ profiles similar to those shown in Figure 4 . The boundary conditions, solver settings, and parameters were set similar to those described in Section 4. The CFD simulations were conducted for three incident wind directions: $0^{\circ}, 22.5^{\circ}$, and $45^{\circ}$. In each wind direction, the pedestrian-level mean wind speed ( $5 \mathrm{~mm}$ in model scale) was measured at 78 points near the tall building and was expressed as $K$ value (Equation (1)).

Figures $7(\mathrm{~b})-(\mathrm{d})$ compare the $K$ value in CFD simulation
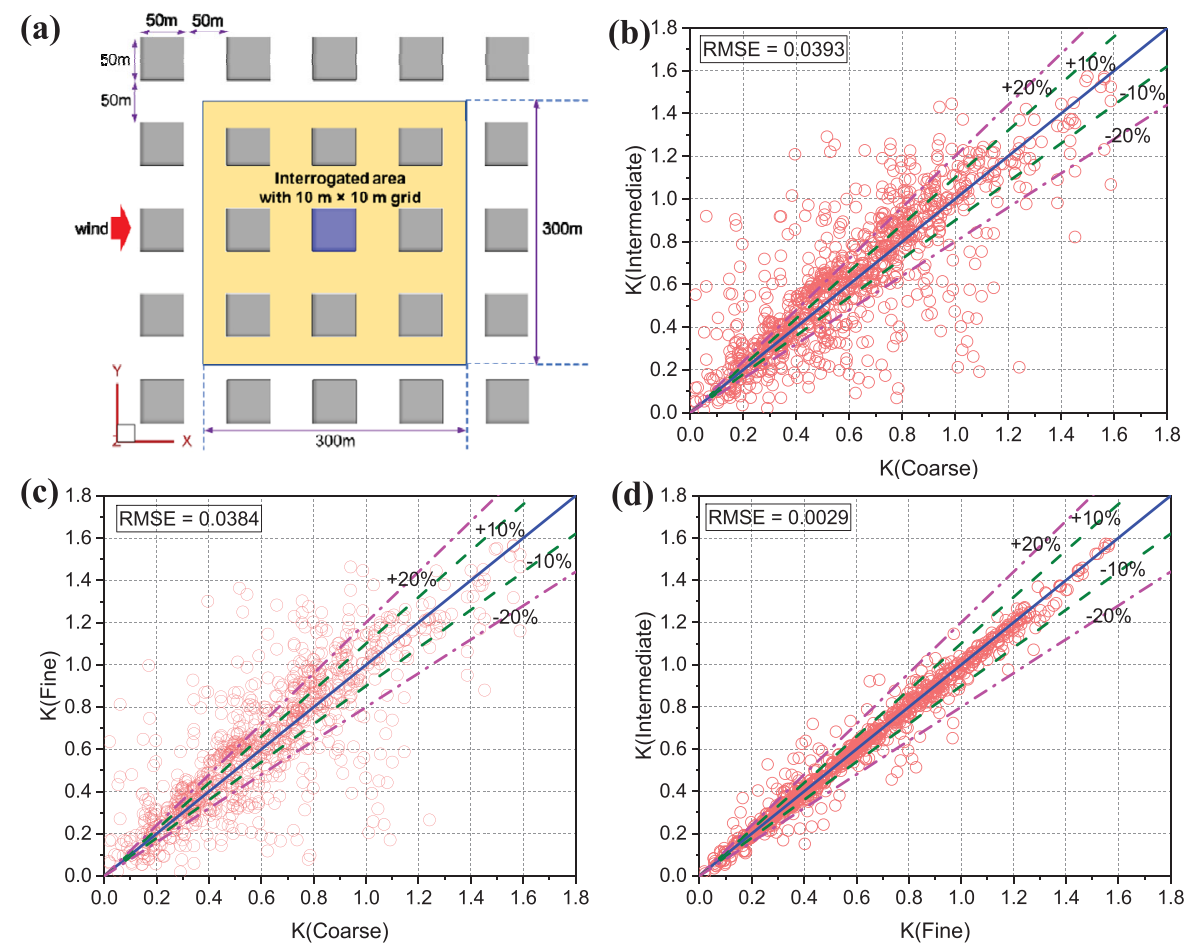

Fig. 6 (a) Grid locations of $K$ value extraction, and the comparison of $K$ value: (b) Coarse-Intermediate grids, (c) Coarse-Fine grids, (d) Fine-Intermediate grids 
(a)



(c)

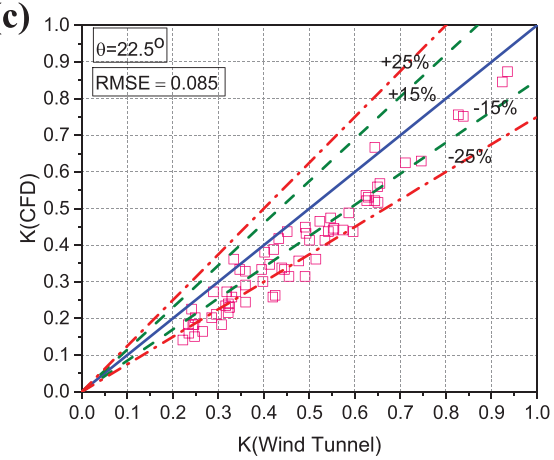

(b)

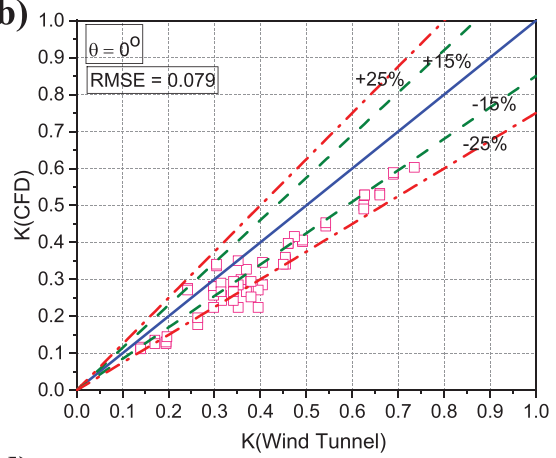

(d)

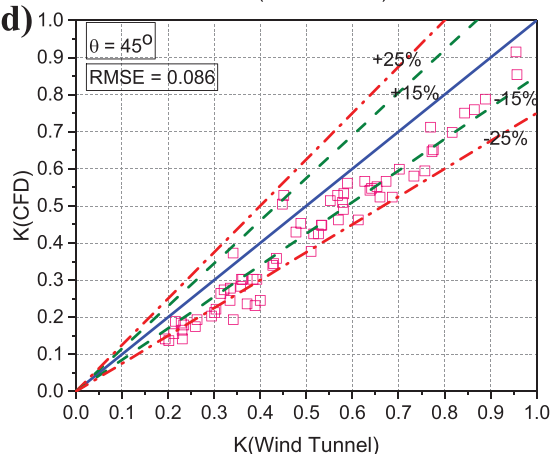

Fig. 7 (a) Arrangement of the tall building and low-rise buildings, and comparison of the wind speed ratio $(K)$ from wind tunnel tests (WT) and CFD simulations (CFD) for wind incidence angles: (b) $0^{\circ}$, (c) $22.5^{\circ}$, and (d) $45^{\circ}$

and wind tunnel test for the three incident wind directions. In general, the $K$ value obtained in CFD simulation is lower than the corresponding $K$ value in wind tunnel test with larger deviations in smaller $K$ values and fairly good agreement found for high $K$ values. This observation suggests a general trend of CFD simulation that under-predicts low mean wind speed in weak wind circulation and is more accurate in modeling high-speed wind flows. Nonetheless, the RSME of $K$ in the three incident wind directions are comparable $\left(\mathrm{RSME}=0.079,0.085,0.086\right.$ in $\theta=0^{\circ}, 22.5^{\circ}$, and $45^{\circ}$, respectively), indicating a similar degree of discrepancy between the data from CFD simulation and wind tunnel test in any incident wind direction.

\section{Results}

\subsection{PLWE near a square-shaped super-tall building}

Figure 8 shows how magnitude of maximum normalized wind speed ratio $\left(K_{\max }\right)$ varies with height of a square-shaped building as reported in two previous studies: Stathopoulos (1985) and Xu et al. (2017), using wind tunnel tests, and the current study, using CFD simulation. The two previous wind tunnel studies indicate a steady growth in $K_{\max }$ with increasing building height, for example, $K_{\max }$ has been magnified from 1.5 to 2 as building height increased from $180 \mathrm{~m}$ to $400 \mathrm{~m}$. Notably, the current CFD study reports a smaller $K_{\max }$ of 1.53 near a $400 \mathrm{~m}$ super-tall building in a regular urban area



Fig. 8 Variation in $K_{\max }$ with height of square-shaped buildings

compared with $K_{\max }=2$ near an isolated super-tall building with similar dimensions. The reduction in $K_{\max }$ of the current study is attributed to the wind sheltering and aerodynamic roughness induced by the surrounding buildings, which subsequently weaken the wind circulation in the regular urban area. However, after the construction of a super-tall building, pedestrians are exposed to more than $50 \%$ intensified wind flows and experienced a 2.7-fold larger wind force on bodies than they experienced before in the regular urban area.

Figures 9(a), (c), and (e) show the distribution of $K$ and pedestrian wind comfort in a group of SQB in Calm and Windy climates. In the group of SQB, a major portion of the PLWE is occupied by deaccelerated wind speeds with 

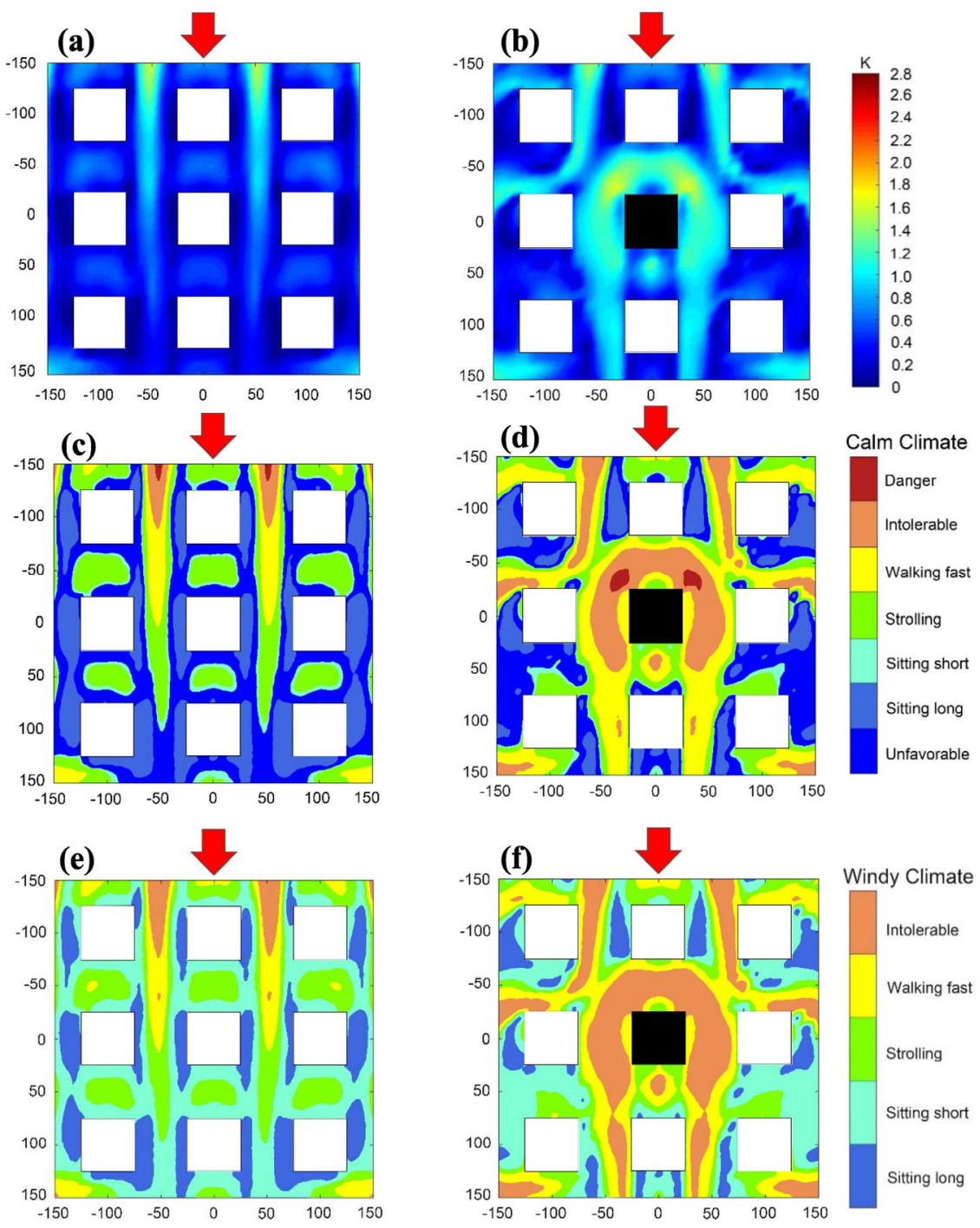

Fig. 9 Distribution of $K$ near: (a) SQB, (b) SQU; wind comfort near (c) SQB, (d) SQU in Calm climate; wind comfort near (e) SQB, (f) SQU in Windy climate

$K \leq 0.6$, except the two small areas with high wind speeds at the upstream edge (Figure 9(a)), where two fairly intense wind jets exist. The areas in this wind environment can be rated as "Unfavorable", "Sitting long" and "Strolling" in Calm climate (Figure 9(c)), and in Windy climate, these areas are suitable for "Siting short" and "Walking fast" (Figure 9(e)). After the construction of the super-tall building, pedestrianlevel wind speed intensifies near the building (Figure 9(b)) and the area bounded by the surrounding SQBs transforms from acceptable wind comfort (i.e., "Sitting long", "Sitting short", and "Strolling") to wind discomfort with "Walking fast", "Intolerable" and even "Dangerous" wind conditions in Calm climate. Pedestrians in Windy climate experience high-degree of wind discomfort because of the high wind speeds due to the intense separation layers formed at the windward corners of the super-tall building. High wind speeds create "Intolerable" wind conditions over a large area, which is not suitable for leisure activities such as "Sitting long" or "Strolling" on the roadsides. (Figure 9(f)).

Figure 10 shows areas of wind comfort classes calculated near the group of SQB and SQU in Calm and Windy climates in $\theta=0^{\circ}, 22.5^{\circ}, 45^{\circ}$. The area with a particular wind comfort class is expressed as a percentage with respect to the interrogated area of $300 \mathrm{~m} \times 300 \mathrm{~m}$ (Figures 9(a) and (d)). The area of wind comfort $\left(A_{\text {com }}\right)$ near SQB in Calm climate is $58.19 \%$ in $\theta=0^{\circ}$ while $31.74 \%$ area is rated as "Unfavorable". "Unfavorable" area becomes smaller, 24.56\% and $25.98 \%$ in $\theta=22.5^{\circ}$ and $45^{\circ}$ but at the same time $A_{\text {com }}$ decreases from $58.19 \% \%$ to $43.47 \%$ as $\theta$ changed from $0^{\circ}$ to $45^{\circ}$ (Figure 10(a)). Compared to a $14.72 \%$ decrease in $A_{\text {com }}$ near SQB in Calm climate, $A_{\text {com }}$ near SQU reduces by $7.19 \%$ despite the area rated as "Dangerous" gradually grows in $\theta=22.5^{\circ}$ and $45^{\circ}$. Indeed, in $\theta=22.5^{\circ}$, and $45^{\circ}, 6.54 \%$ and 9.55\% areas rated as "Dangerous" are found near SQU in 

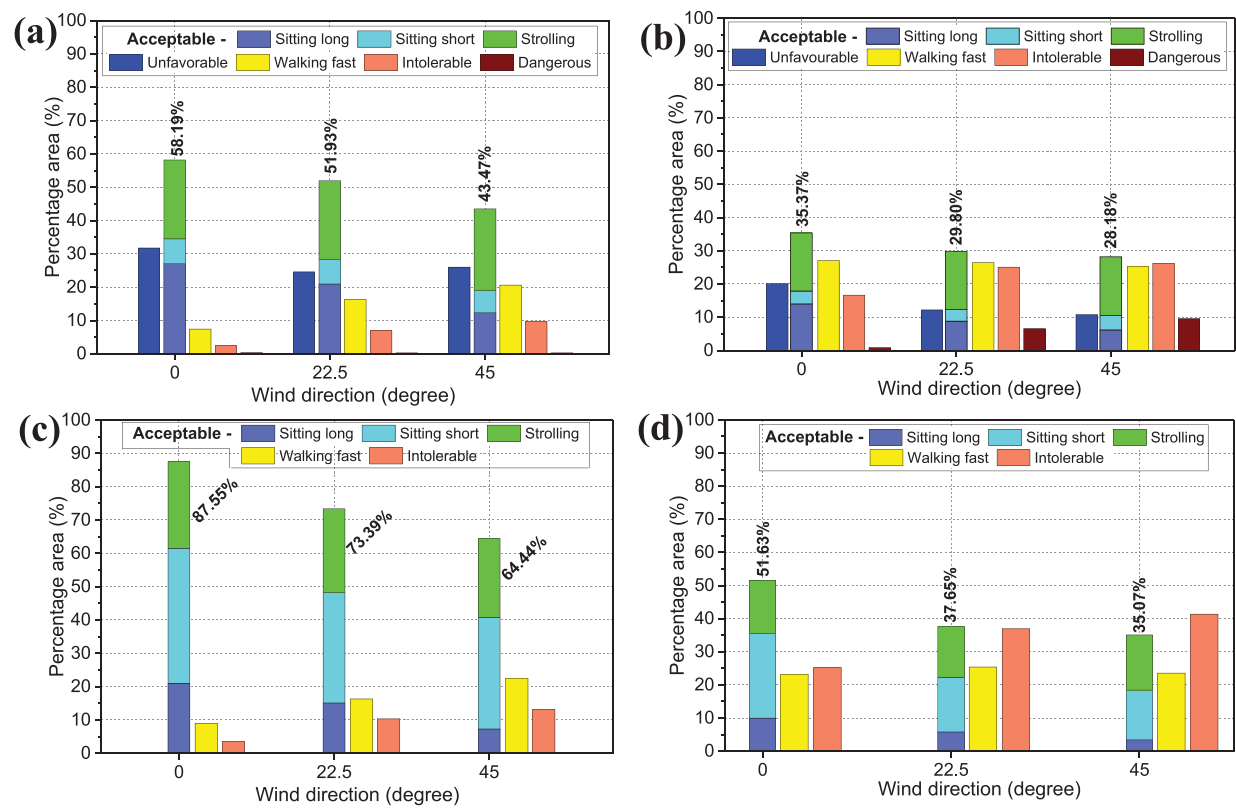

Fig. 10 Percentage area of wind comfort classes near: (a) SQB and (b) SQU in Calm climate and (c) SQB and (d) SQU in Windy climate in $\theta=0^{\circ}, 22.5^{\circ}, 45^{\circ}$

Calm climate (Figure 10(b)). A more than 35\% reduction in $A_{\text {com }}$ is found in Windy climate after constructing SQU in the group of SQBs. Moreover, $A_{\text {com }}$ near SQU in Windy climate steadily decreases from $51.63 \%$ to $35.07 \%$ as $\theta$ changed from $0^{\circ}$ to $45^{\circ}$. The shrinkage of $A_{\text {com }}$ near SQU is mainly due to a more than $10 \%$ reduction of the area suitable for "Sitting short" compared to 1 to $6 \%$ decrease in the areas assigned for "Sitting long" and "Strolling" as $\theta$ changed from $0^{\circ}$ to $45^{\circ}$ (Figure $10(\mathrm{~d})$ ). Moreover, larger areas rated as "Intolerable" occur near SQU in Windy climate indicating high vulnerability of pedestrians exposing to high-speed wind flows near the super-tall building.

\subsection{Pedestrian wind comfort near a super-tall building with "Basic shapes"}

A previous study (Zhang et al. 2020) has found that PLWE near a super-tall building with basic shapes strongly depends on two building features: (1) shape of the building corners (e.g. sharp or blunt) and (2) aspect ratio of building plan area (i.e., building width-to-depth ratio). The effect of building corners on pedestrian wind comfort can be inferred from the distribution of wind comfort classes near TRI and CIR (Figure 11). For instance, the area downstream TRI has poor pedestrian wind comfort in $\theta=0^{\circ}$ as a $29.54 \%$ area is labeled as "Intolerable" (Figure 12(f)), while CIR generates a smaller area of $18.14 \%$ rated as "Intolerable" (Figure 12(g)). The areas rated as "Intolerable" near TRI rise to $46.21 \%$ in $\theta=45^{\circ}$ in contrast to $25.62 \%$ of a small area marked as "Intolerable" found near CIR.
REC and ELL - two buildings with the plan aspect ratio (width/depth) larger than one - have a similar trend, where $A_{\text {com }}$ near the former building is smaller than that of the latter in all the tested incident wind directions (Figures 12(e) and $(\mathrm{h})$ ). Another striking feature of wind comfort near REC and ELL is the noticeably high $A_{\text {com }}$ reported in $\theta=90^{\circ}$ than that in $\theta=0^{\circ}$. For instance, $A_{\text {com }}$ near REC and ELL in Calm climate increases from $34.17 \%$ to $43.50 \%$ and $36.75 \%$ to $54.44 \%$, respectively, as $\theta$ changed from $0^{\circ}$ to $90^{\circ}$ (Figures 12(a) and (d)). In Windy climate, the $A_{\text {com }}$ increase is from $40.11 \%$ to $57.36 \%$ and $49.29 \%$ to $69.20 \%$ for REC and ELL, respectively (Figures 12(e) and (h)).

Figure 13 depicts the differences in $A_{\text {com }}$ of REC and ELL, which are indeed attributed to the existence of areas with high wind speeds near the buildings (Figure 12). For example, in Calm climate, $22.01 \%$ and $7.20 \%$ areas rated as "Intolerable" and "Dangerous" are found near REC in $\theta=$ $0^{\circ}$, but these areas have become smaller of $9.74 \%$ and $0.05 \%$ in $\theta=90^{\circ}$. It should be noted that, in $\theta=90^{\circ}$, the reduction of the areas rated as "Intolerable" and "Dangerous" in Calm climate has not only escalated $A_{\text {com }}$ but also swells the area labeled as "Unfavorable" in the vicinity of REC and ELL (Figures 13(b) and (d)). In Windy climate, the increase of $A_{\text {com }}$ near REC in $\theta=90^{\circ}$ is mainly attributed to the larger expansion of the areas assigned for "Sitting short" and "Strolling" than the slight increase of the area suitable for "Sitting long" (Figure 12(e)). Indeed, REC and ELL in Windy climate have higher $A_{\text {com }}=57.36 \%$ and $69.20 \%$ in $\theta=90^{\circ}$ than $A_{\text {com }}=51.63 \%$ of SQU. The significant variations in $A_{\text {com }}$ of REC and ELL in $\theta=0^{\circ}$ and $90^{\circ}$ are ascribed to the 

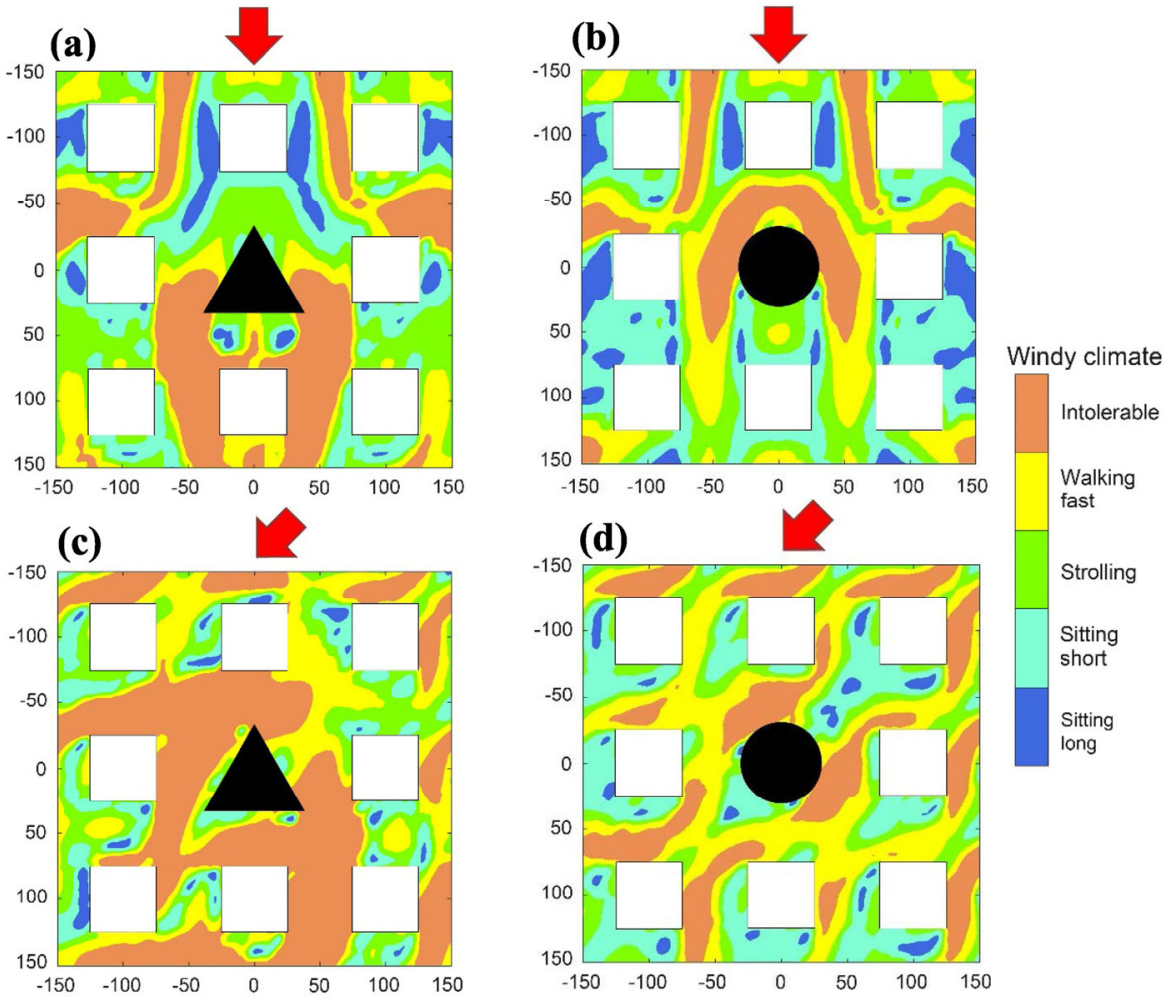

Fig. 11 Distribution of wind comfort classes near: (a) TRI and (b) CIR in $\theta=0^{\circ}$, and (c) TRI and (d) CIR in $\theta=45^{\circ}$

degree of wind blockage by the buildings, which is maximum and minimum at $\theta=0^{\circ}$ and $90^{\circ}$, respectively (Zhang et al. 2020).

\subsection{Effect of number of building sides on pedestrian} wind comfort

In addition to the shape of building corners, the number of building sides can be another reason for the dissimilar variation in wind comfort found near TRI and CIR, which have three and an infinite number of building sides, respectively. The effect of the number of building sides on pedestrian wind comfort is further investigated using two "Polygonal" buildings: a pentagonal-shaped building (PEN) and an octagonal-shaped building (OCT).

Figure 14 shows how areas with different wind comfort classes near PEN and OCT vary with five incident wind directions: $0^{\circ}, 22.5^{\circ}, 45^{\circ}, 90^{\circ}$, and $180^{\circ}$ in Calm and Windy climates. Except in $\theta=22.5^{\circ}$, PEN has larger $A_{\text {com }}$ values than does SQU in Calm climate, suggesting that pentagonalshaped super-tall buildings are advantageous in providing pedestrian wind comfort. However, in Calm climate, PEN in $\theta=0^{\circ}, 90^{\circ}$, and $180^{\circ}$ creates larger and smaller areas rated as "Dangerous" and "Unfavorable" wind conditions, respectively, than SQU does. OCT, on the other hand, has larger $A_{\text {com }}$ in both Calm and Windy climates than that of SQU in all tested incident wind directions. In particular, the area labeled as "Dangerous" near OCT in Calm climate is less than $1 \%$ in all wind directions, and despite OCT creates slightly larger areas rated as "Unfavorable" than SQU.

Figure 15 shows a profound effect of orientation of the sharp building corners of PEN on pedestrian wind comfort in various incident wind directions. For instance, area categorized as "Unfavorable" near PEN in Calm climate varies by $10.81 \%, 13.25 \%, 13.93 \%, 15.41 \%$ and $18.75 \%$ in $\theta=0^{\circ}, 22.5^{\circ}, 45^{\circ}, 90^{\circ}$, and $180^{\circ}$, respectively. In contrast, the wind comfort classes do not vary significantly near OCT. Moreover, the distribution of comfort classes near OCT is similar to that of CIR in all tested incident wind direction, and thereby it can be assumed that the pedestrian wind comfort near a super-tall building with an eight-side plan is insensitive to incident wind direction, same as a building with infinite-sides, i.e., circular-shaped plan.

\subsection{Effect of corner modification}

Several studies have suggested that corner modifications are effective in reducing magnitude and area with high wind speeds near buildings (Zhang et al. 2017; Stathopoulos 1985; Jamieson et al. 1992; Uematsu et al. 1992). Two types of corner modifications: corner chamfered and corner cut, are applied to SQU to design two super-tall buildings: CH-SQ and CC-SQ, respectively (Figure 1). 

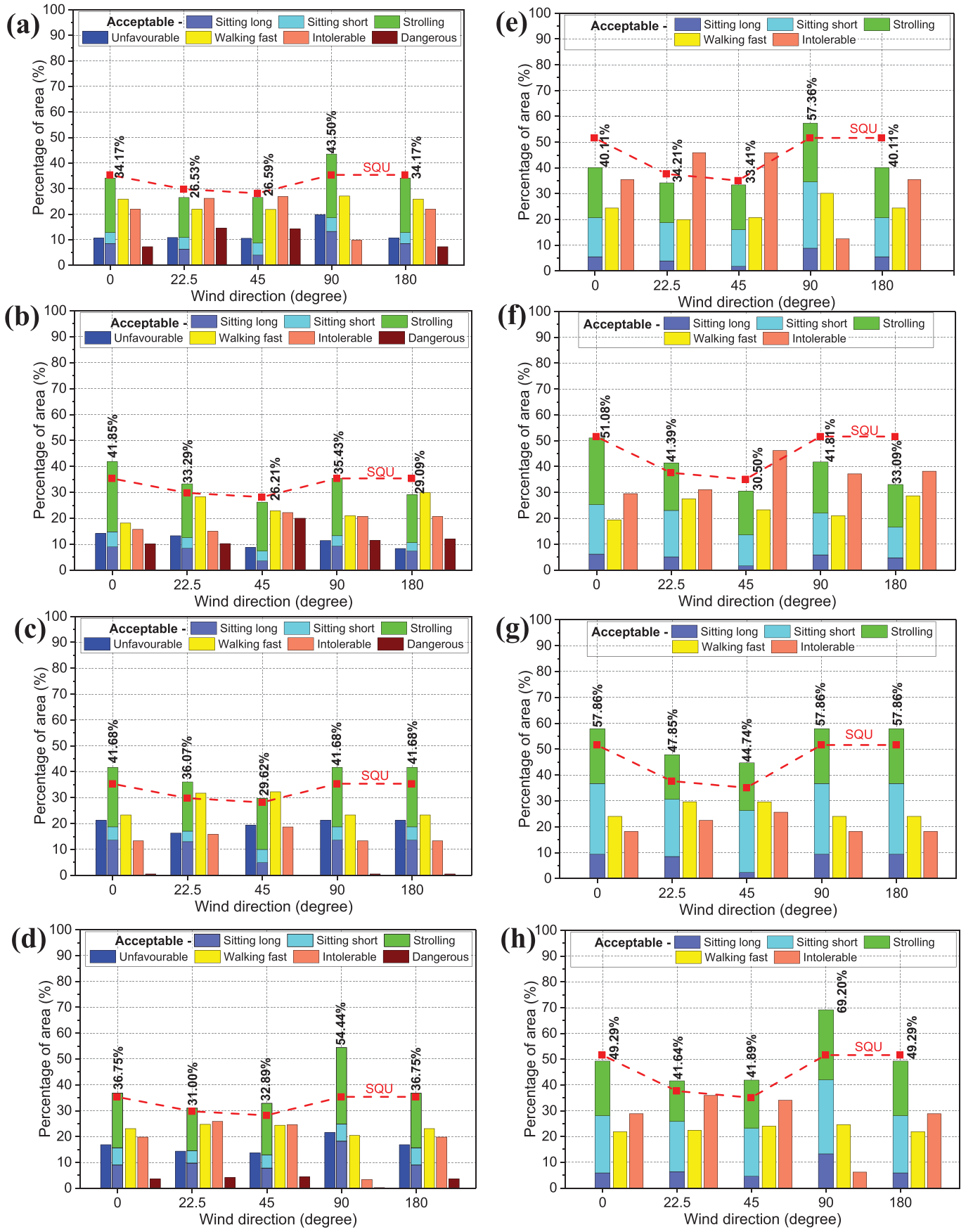

Fig. 12 Percentage area of wind comfort classes near: (a) REC, (b) TRI, (c) CIR, (d) ELL in Calm climate and (e) REC, (f) TRI, (g) CIR, (h) ELL in Windy climate

Figure 16 shows areas with various classes of wind comfort found near CH-SQ and CC-SQ in Calm and Windy climates. The two corner modifications are advantageous in creating the pedestrian wind comfort in both wind climates, in particular, they have larger $A_{\text {com }}$ in Windy climate than SQU does. Moreover, the corner modifications are useful in reducing the areas rated as "Dangerous" in oblique incident wind directions. For example, areas with "Dangerous" wind conditions near CH-SQ and CC-SQ in
Calm climate are $7.38 \%$ and $5.96 \%$ smaller than that of SQU in $\theta=45^{\circ}$. Figure 17 indicates that corner modifications not only suppress the areas rated as "Dangerous" and "Intolerable" near the super-tall building but also minimize the occurrence of these wind conditions in the vicinity of neighboring buildings. The effectiveness of corner modifications in creating pedestrian wind comfort is higher in Windy climate than in Calm climate (Figures 16(c) and (d)). For instance, $A_{\text {com }}$ near CH-SQ and CC-SQ in Windy 


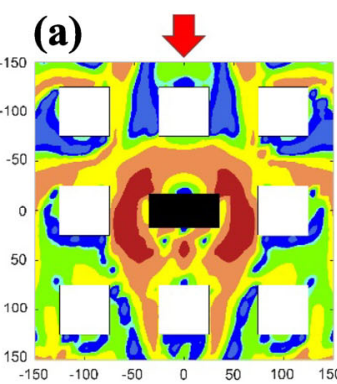

(b)

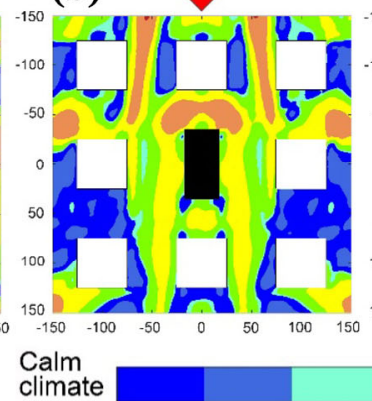

Unfavorable Sitting Sitting

\section{(f)}

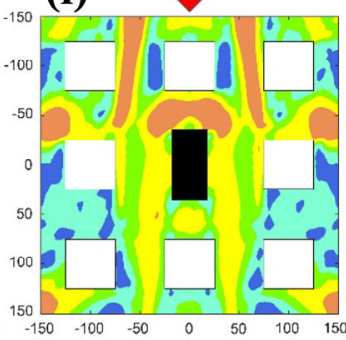

(c)

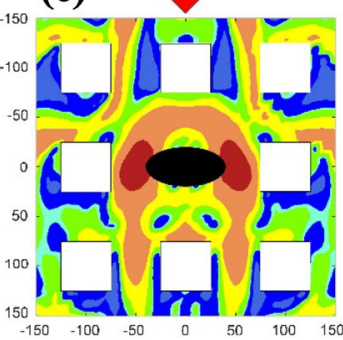

(d)

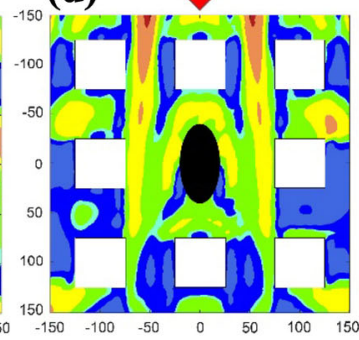

(g)

long short



(h)

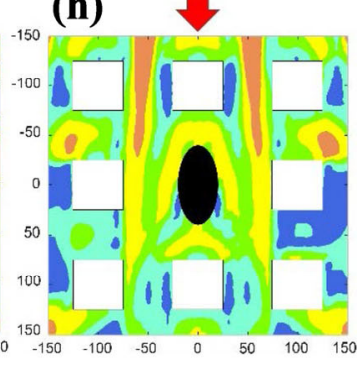

(e)

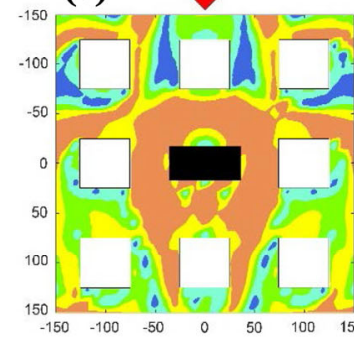

\section{Windy}

climate Sitting Sitting Strolling Walking Intolerable

Fig. 13 Distribution of wind comfort classes near: (a) REC in $\theta=0^{\circ}$, (b) REC in $\theta=90^{\circ}$, (c) ELL in $\theta=0^{\circ}$, (d) ELL in $\theta=90^{\circ}$ in Calm climate and (a) REC in $\theta=0^{\circ}$, (b) REC in $\theta=90^{\circ}$, (c) ELL in $\theta=0^{\circ}$, (d) ELL in $\theta=90^{\circ}$ in Windy climate

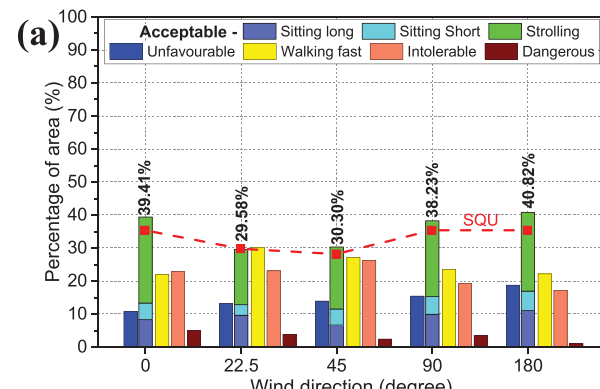

(c)

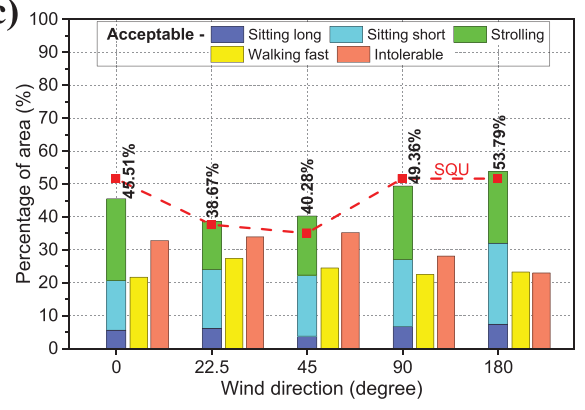

(b)

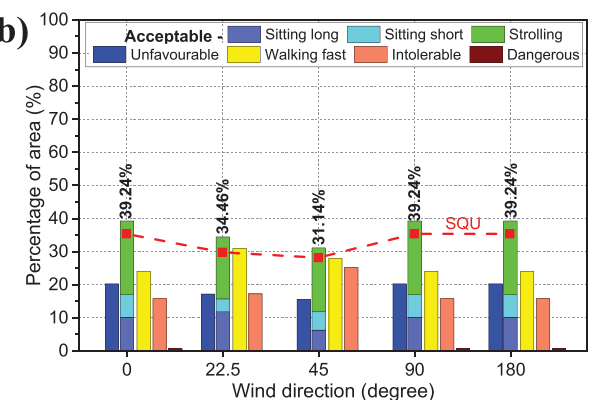

(d)

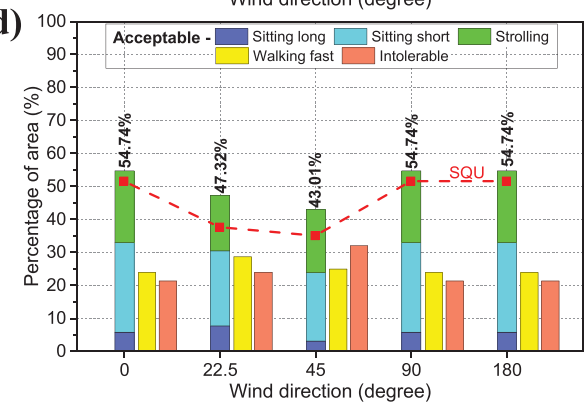

Fig. 14 Percentage area of wind comfort classes near: (a) PEN and (b) OCT in Calm climate and (c) PEN and (d) OCT in Windy climate

climate is $8 \%-1 \%$ higher compared to the counterpart of $A_{\text {com }}$ of SQU. In addition to the enhancement in $A_{\text {com }}$, the areas rated as "Intolerable" in Windy climate shrink more than $4.5 \%$ near CH-SQ and CC-SQ, improving the overall quality of PLWE. Between the two corner modifications, chamfered corners are more effective in eliminating high-speed wind in Windy climate than does corner cut (Figures 17(e) and (f)).

\subsection{Effect of varying building cross-section}

If building dimensions are large, minor aerodynamic 



(f)

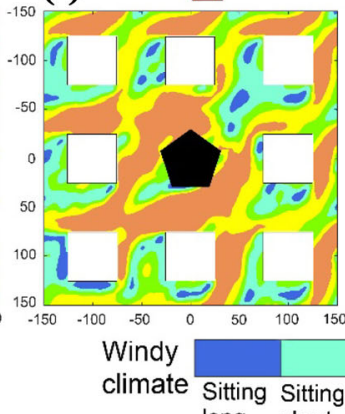

(g)

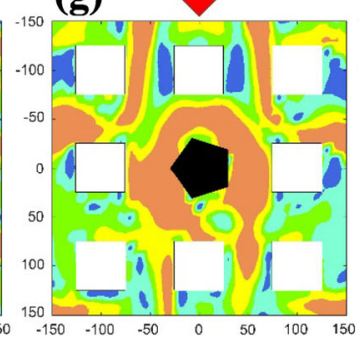

(h)

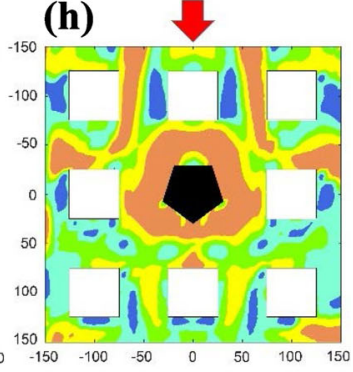
long short

Fig. 15 Distribution of wind comfort classes near PEN in: (a) $\theta=0^{\circ}$, (b) $\theta=45^{\circ}$, (c) $\theta=90^{\circ}$, (d) $\theta=180^{\circ}$ in Calm climate and (e) $\theta=0^{\circ}$, (f) $\theta=45^{\circ}$, (g) $\theta=90^{\circ}$, (h) $\theta=180^{\circ}$ in Windy climate
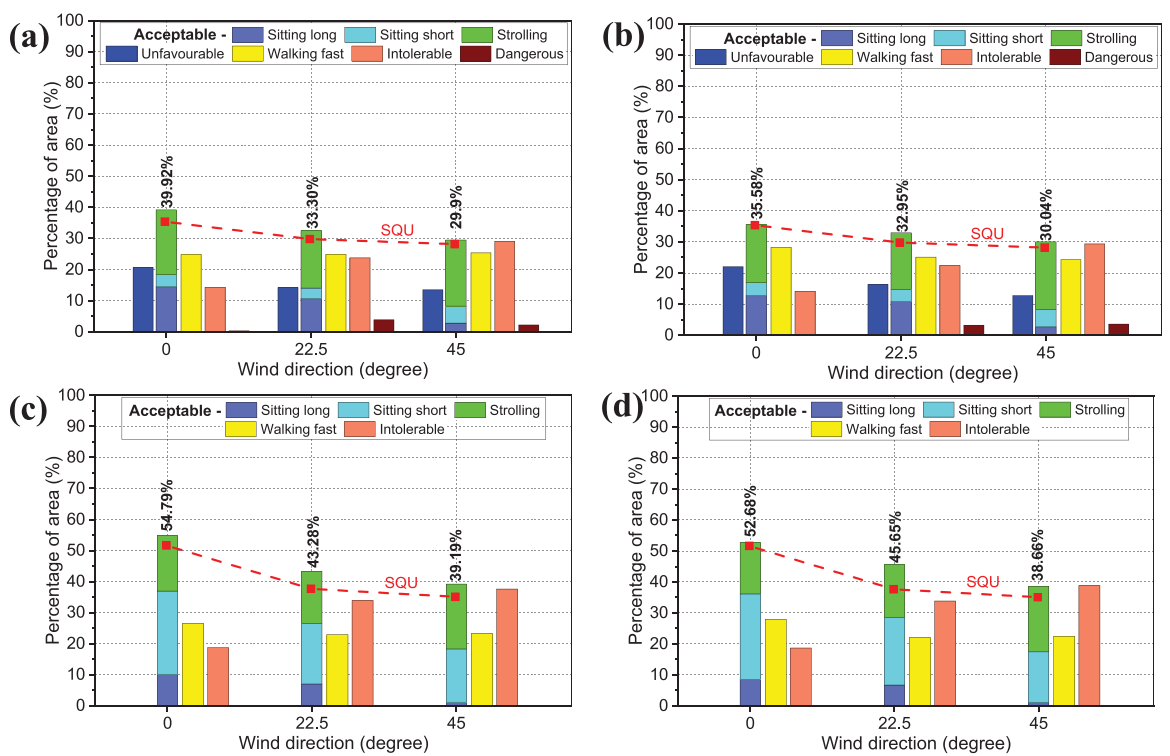

Fig. 16 Percentage area of wind comfort classes near (a) CH-SQ, (b) CC-SQ in Calm climate, and (c) CH-SQ, (d) CC-SQ in Windy climate

modifications such as corner modifications are often found to be inadequate to modify the surrounding wind environment (Stathopoulos 1985; Zhang et al. 2017). In such situations, major aerodynamic modifications, such as varying cross-section along building height, are adopted for tall buildings. The effect of varying cross-section is investigated by adopting 2-side tapered (2TP-SQ) and setback (SB-SQ) configurations for the super-tall building.

Figure 18 shows how areas of wind comfort classes near 2TP-SQ and SB-SQ in Calm and Windy climates vary with incident wind direction. In Calm climate, SB-SQ seems to be advantageous in creating pedestrian wind comfort as it 

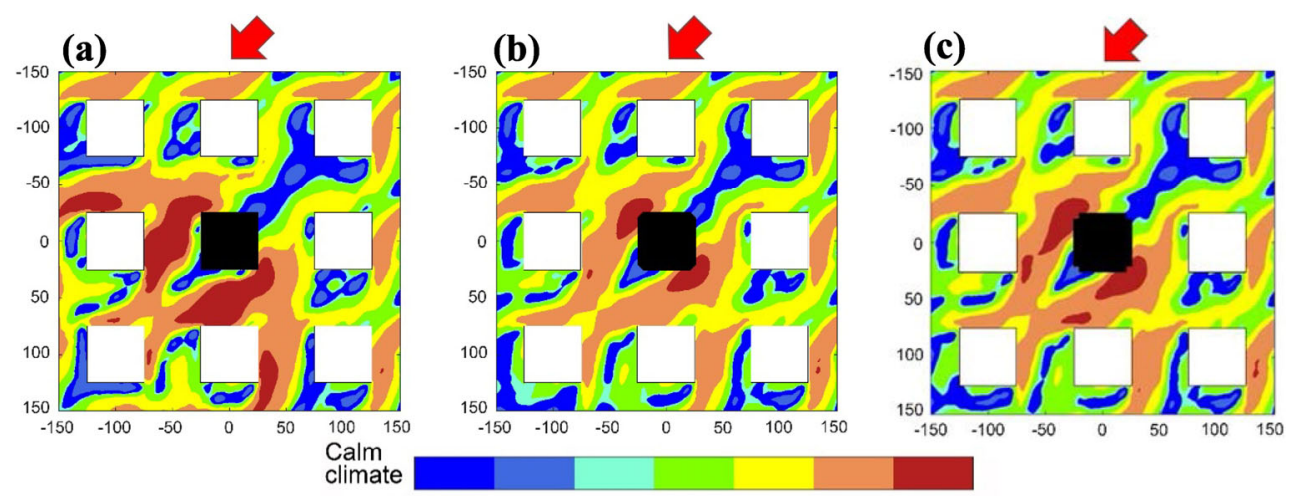

Unfavorable Sitting Sitting Strolling Walking Intolerable Danger
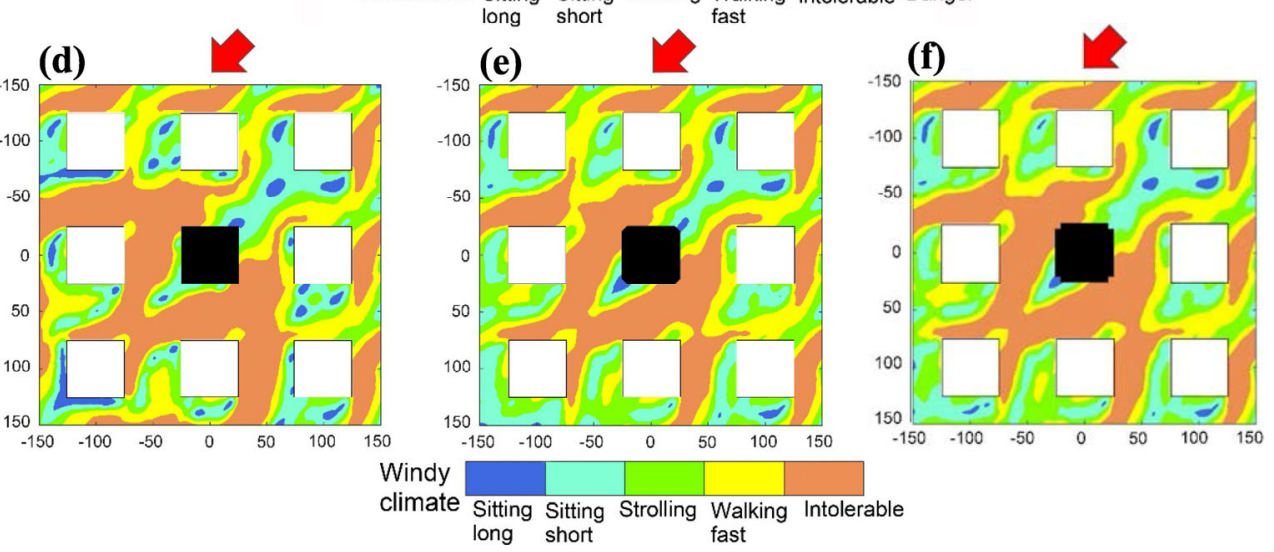

Fig. 17 Distribution of areas with various wind comfort classes near: (a) SQU, (b) CH-SQ, (c) CC-SQ in Calm climate, and (d) SQU, (e) $\mathrm{CH}-\mathrm{SQ}$, (f) CC-SQ in Windy climate in $\theta=45^{\circ}$
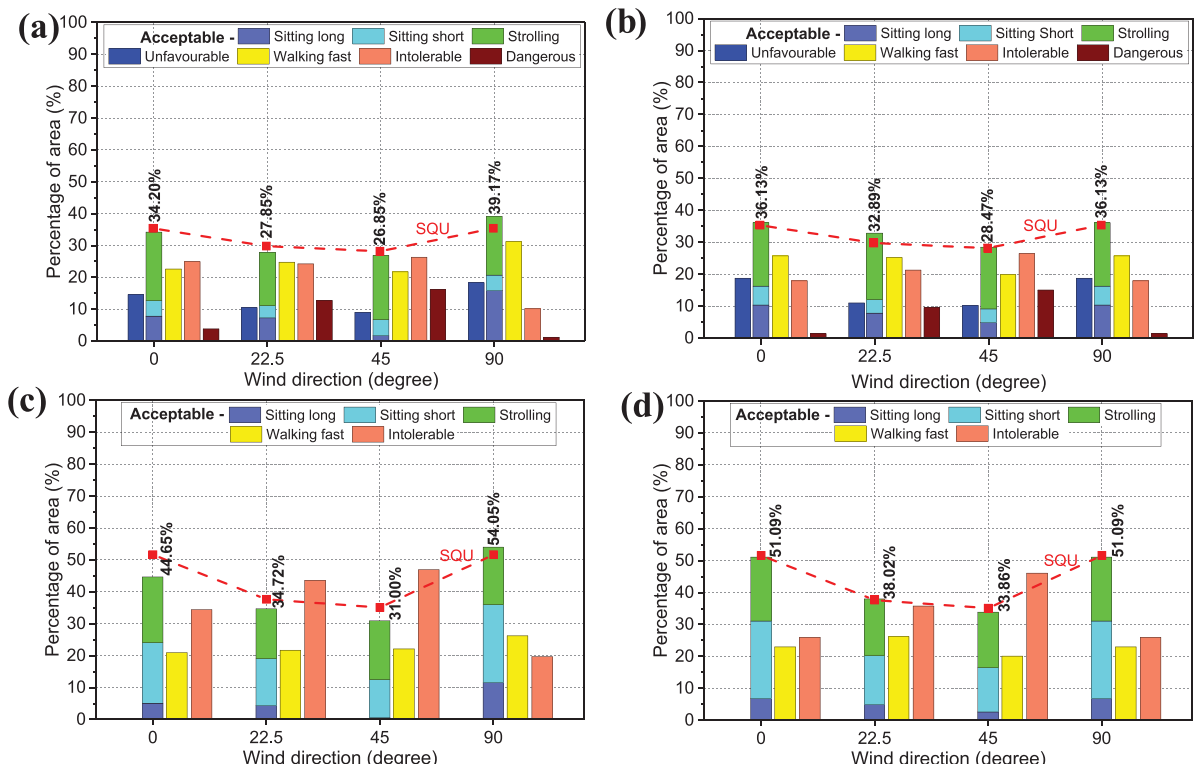

Fig. 18 Percentage area of wind comfort classes near: (a) 2TP-SQ, (b) SB-SQ in Calm climate, and (c) 2TP-SQ, (d) SB-SQ in Windy climate

registers slightly larger $A_{\text {com }}$ in all tested wind directions than does SQU, whereas $2 \mathrm{TP}-\mathrm{SQ}$ records higher $A_{\text {com }}$ only in $\theta=0^{\circ}$. However, the two configurations in Calm climate jeopardize pedestrian wind comfort by swelling the areas ranked as "Dangerous" (Figures 19(a) and (b)). An example is the area rated as "Dangerous" near 2TP-SQ and SB-SQ in Calm climate are $12.74 \%$ and $9.55 \%$ in $\theta=22.5^{\circ}$, and $16.15 \%$ and $15.05 \%$ in $\theta=45^{\circ}$, which are larger than the corresponding areas found near SQU. Figures 18(c) and (d) indicate less effectiveness of 2TP-SQ and SB-SQ in Windy 

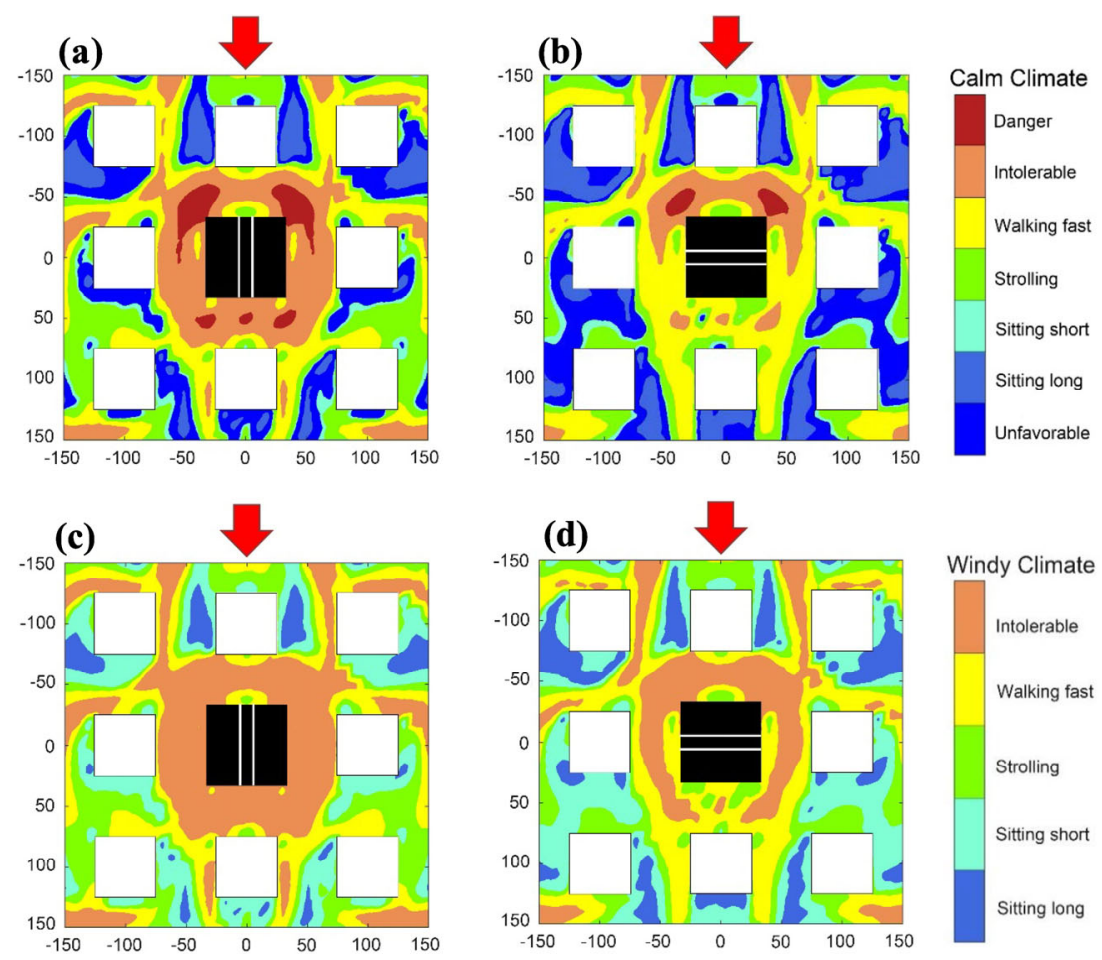

Fig. 19 Distribution of wind comfort classes near 2TP-SQ in: (a) $\theta=0^{\circ}$, (b) $\theta=90^{\circ}$ in Calm climate, and (c) $\theta=0^{\circ}$, (d) $\theta=90^{\circ}$ in Windy climate

climate except in the cases of 2TP-SQ in $\theta=90^{\circ}$ and SB-SQ in $\theta=22.5^{\circ}$, where the two buildings have larger $A_{\text {com }}$ than SQU.

Compared to SB-SQ, the pedestrian wind comfort near 2TP-SQ shows a strong dependency on incident wind direction, particularly for $\theta=0^{\circ}$, and $90^{\circ}$, where $2 \mathrm{TP}-\mathrm{SQ}$ has the smallest and largest building frontal areas. For example, with flat and smallest frontal area, 2TP-SQ in $\theta=$ $0^{\circ}$ creates large areas categorized as "Dangerous" in Calm climate (Figure 19(a)) and areas rated as "Intolerable" in Windy climate (Figure 19(c)). In $\theta=90^{\circ}$, where 2TP-SQ has a sloped and large windward side, pedestrian wind comfort has been improved near the building as the areas previously rated as "Intolerable" in Calm and Windy climates transformed into the areas suitable for "Strolling" and "Walking fast" (Figures 19(b) and (d)).

\subsection{Effect of building openings}

Several recent studies have investigated the potential of building openings as a design component for controlling the surrounding wind environment in Calm and Windy Climates (Tse et al. 2017b; Zhang et al. 2017, 2018; van Druenen et al. 2019). This study adopts two types of building openings: openings near the top of the building (TOP) and opening at lower height by using a 'lift-up' design (LIF) to assess pedestrian wind comfort near a super-tall building with building openings.

Figure 20 shows the distribution of percentage area of wind comfort classes near LIF and TOP in Calm and Windy climates. In Calm climate, both LIF and TOP have slightly higher $A_{\text {com }}$ in $\theta=0^{\circ}$ compared to SQU, but both buildings with openings generate larger areas rated as "Dangerous" in the vicinity. In particular, LIF creates the largest areas rated as "Dangerous" wind conditions in all tested wind directions. The areas rated as "Dangerous" found on the lateral sides of LIF (Figure 21) are due to two sets of separation layers generated by the center core and elevated structure of the building (Tse et al. 2017b). Conversely, TOP in Calm climate generates larger areas categorized as "Unfavorable" than LIF, but these areas near TOP $\left(20.71 \%, 12.14 \%\right.$ and $9.72 \%$ in $\left.\theta=0^{\circ}, 22.5^{\circ}, 45^{\circ}\right)$ are comparable in size with those found near SQU $(20.08 \%$, $12.18 \%$ and $10.77 \%$ in $\left.\theta=0^{\circ}, 22.5^{\circ}, 45^{\circ}\right)$. In Windy climate, TOP in $\theta=0^{\circ}$ is the only case found to be advantageous in creating larger areas with "Acceptable wind comfort", while all other cases, both LIF and TOP generate larger areas classified as "Intolerable". For instance, the areas ranked as "Intolerable" near LIF in Windy climate are 6\% to 3\% larger than those found near SQU. A striking feature of the distributions of areas with wind comfort classes near TOP (Figures 21(b), (d), (f), (h)) is its close resemblance to that of SQU. It is, therefore, prudent to assume that a super-tall building with a building opening near the roof level has less 

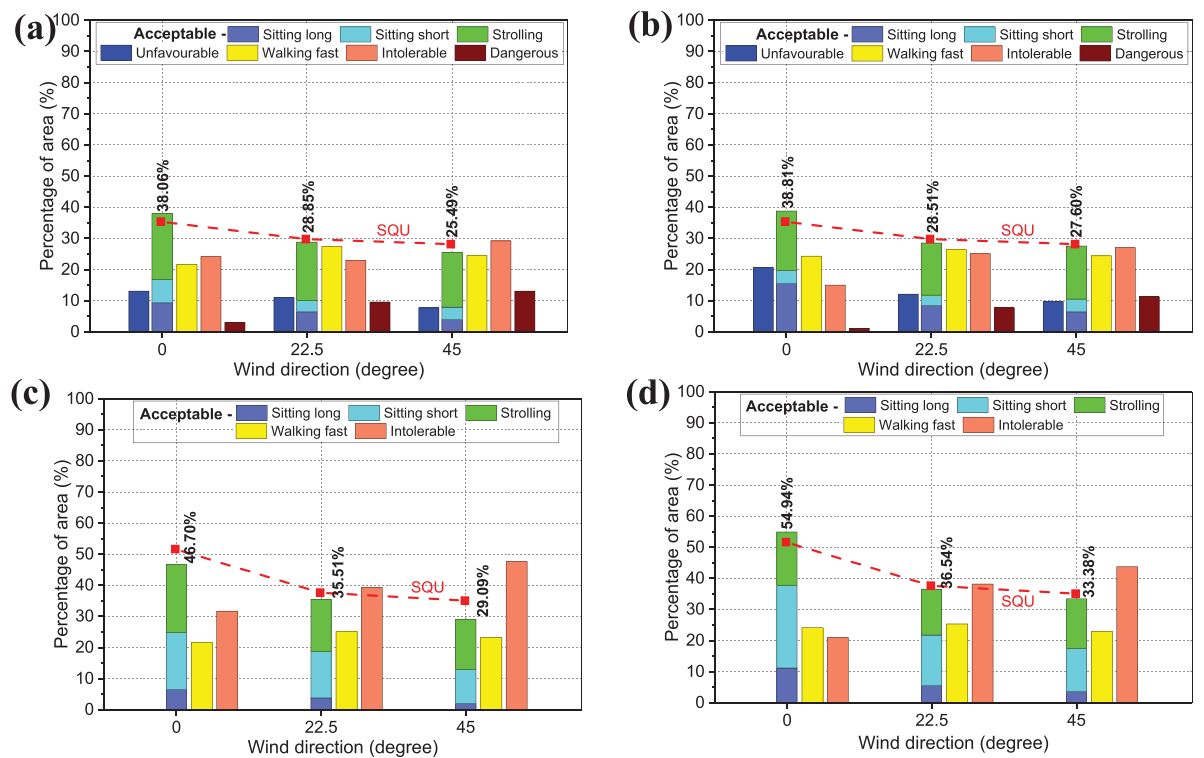

Fig. 20 Percentage area of wind comfort classes near: (a) LIF, (b) TOP in Calm climate, and (c) LIF, (d) TOP in Windy climate



(b)

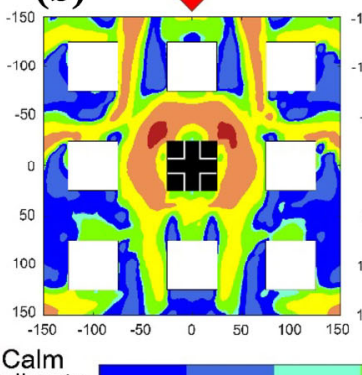

(c)

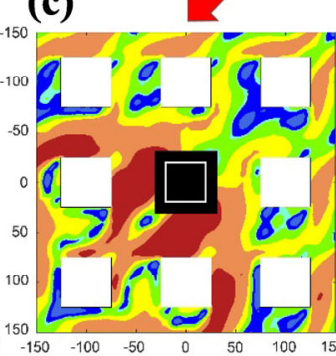

(d)

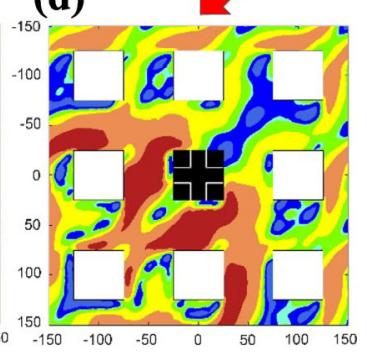

climate

Unfavorable Sitting Sitting Strolling Walking Intolerable Danger

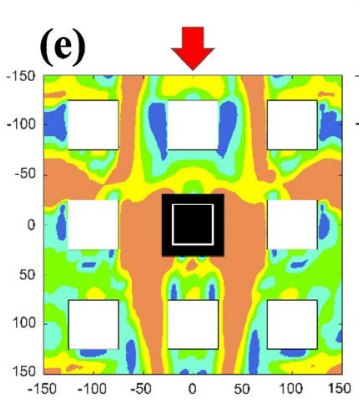

(f)

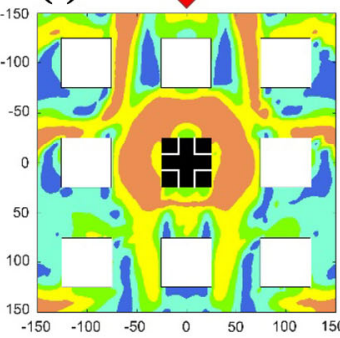

(g)

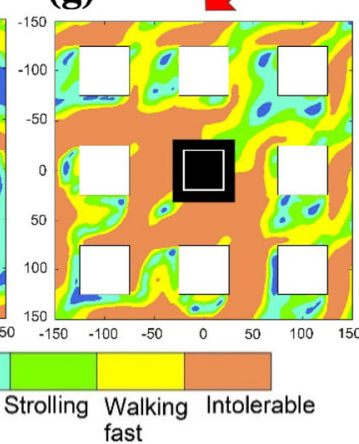

Windy

climate Sitting Sitting Strolling Walking Intolerable
long short (h)

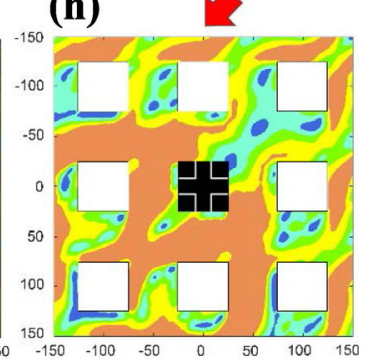

Fig. 21 Distribution of areas with various wind comfort classes near: (a) LIF in $\theta=0^{\circ}$, (b) TOP in $\theta=0^{\circ}$, (c) LIF in $\theta=45^{\circ}$, (d) TOP in $\theta=$ $45^{\circ}$ in Calm climate, and (e) LIF in $\theta=0^{\circ}$, (f) TOP in $\theta=0^{\circ}$, (g) LIF in $\theta=45^{\circ}$, (h) TOP in $\theta=45^{\circ}$ in Windy climate

effect on pedestrian wind comfort.

6.7 Effect of varying cross-section and orientation of the building

Pedestrian wind comfort near a super-tall building with varying cross-section and orientation is investigated using a tilted (TL-SQ), and a setback square-shaped super-tall building with rotated setback sections (SB-45R-SQ). TL-SQ has a $7^{\circ}$ inclination to the vertical axis, and SB-45R-SQ has a $45^{\circ}$ rotation of its setback sections. In all tested cases, SB-45R-SQ in Calm climate has larger $A_{\text {com }}$ than SQU, indicating advantageous of the setback-rotation building design in improving pedestrian wind comfort in Calm 
climate (Figure 22(a)). However, SB-45R-SQ tends to swell the areas with "Dangerous" and "Intolerable" wind conditions in Calm and Windy climates compared to SQU. For instance, SQ-45R-SQ in $\theta=45^{\circ}$ generates $16.03 \%$ and $43.85 \%$ of areas rated as "Dangerous" and "Intolerable" in Calm and Windy climates compared with the corresponding areas of 9.55\% and $41.35 \%$ found near SQU. Notably, these areas with extreme wind discomfort in $\theta=45^{\circ}$ do not confine into the vicinity of SB-45R-SQ but rather extends beyond its downstream SQBs (Figures 23(b) and (d)). Moreover, pedestrian wind comfort near SB-45R-SQ strongly depends on incident wind direction, for example, in Windy climate, the areas rated as suitable for "Sitting long" and "Sitting short" shrink from $8.77 \%$ and $20.55 \%$ in $\theta=0^{\circ}$ to $2.90 \%$ and $14.23 \%$ in $\theta=45^{\circ}$ (Figure 22(c)).

With respect to incident wind direction, TL-SQ has


Fig. 22 Percentage area of wind comfort classes near: (a) SB-45R-SQ, (b) TL-SQ in Calm climate, and (c) SB-45R-SQ, (d) TL-SQ in Windy climate
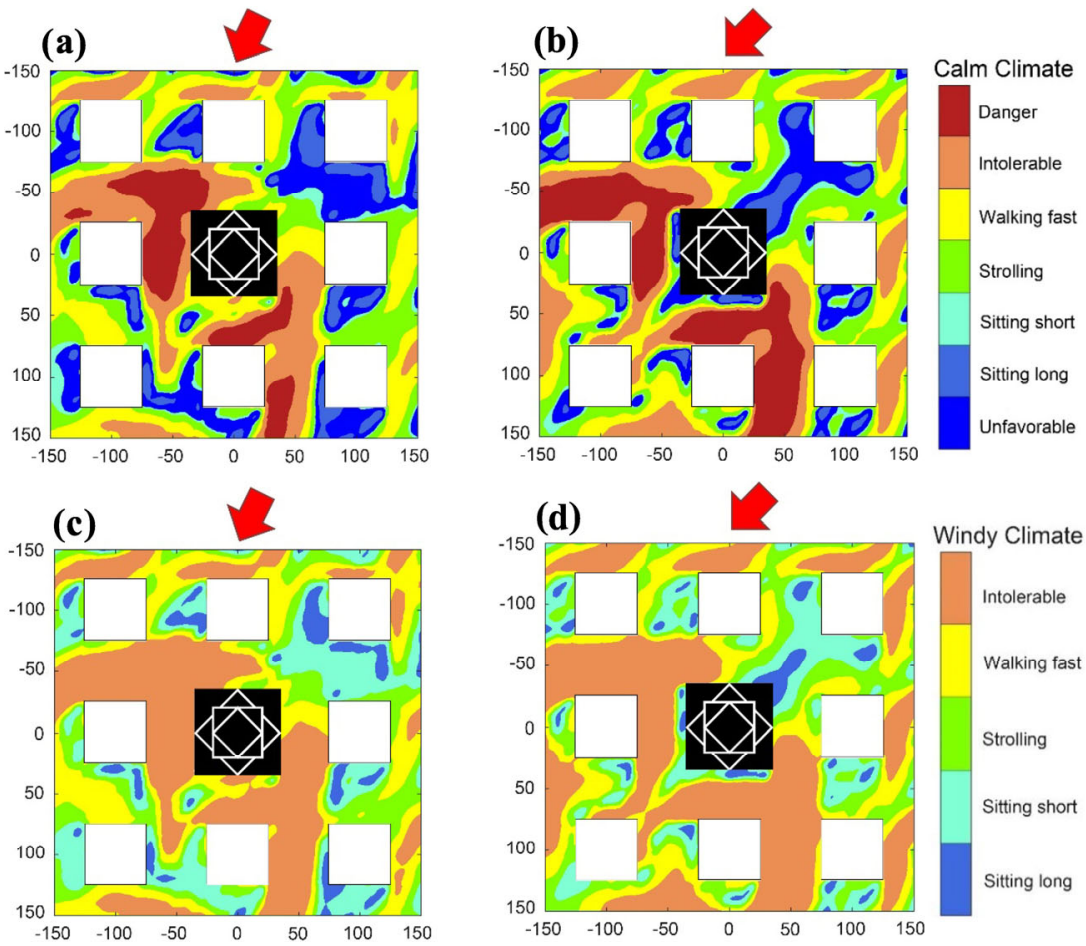

Fig. 23 Distribution of pedestrian wind comfort classes near SB-45R-SQ in: (a) $\theta=22.5^{\circ}$ and (b) $\theta=45^{\circ}$ in Calm climate, and (c) $\theta=$ $22.5^{\circ}$ and (d) $\theta=45^{\circ}$ in Windy climate 
different inclinations: backward, forward, and side with the vertical axis in $\theta=0^{\circ}, 180^{\circ}$, and $90^{\circ}$, respectively. The inclination of TL-SQ has a strong influence on pedestrian wind comfort, for example, the areas rated as "Intolerable" near TL-SQ with backward inclination (or in $\theta=0^{\circ}$ ) are $16.52 \%$ and $23.78 \%$ in Calm and Windy climates, but with forward inclination ( or in $\theta=180^{\circ}$ ), these areas increase to $21.28 \%$ and $28.54 \%$ (Figure 22). The influence of the orientation of TL-SQ on pedestrian wind comfort can be further inferred from Figure 24, where TL-SQ with backward inclination generates smaller and larger areas fitting for "Sitting long" and "Walking fast" in Calm and Windy climates compared to TL-SQ with a forward inclination. The distribution of areas with wind comfort classes becomes asymmetric about the centerline of TL-SQ with side inclination ( or in $\theta=90^{\circ}$ ), where the areas rated as "Intolerable" in Calm and Windy climates unevenly spread around the building (Figures 24(c) and (g)). TL-SQ is advantageous in creating an acceptable PLWE in $\theta=45^{\circ}$, where $A_{\text {com }}$ of TL-SQ in Calm and Windy climates is and $13.34 \%$ and $19.07 \%$ higher than that of SQU (Figures 22(b) and $(\mathrm{d})$.

\section{Discussion}

Despite valuable insights on pedestrian wind comfort near a super-tall building with various configurations in an urban area provided here, the findings of this study should be interpreted for engineering applications baring some limitations, as listed follow:

- The 3D RANS technique used for this study has its inherent drawbacks, such as underestimating the magnitude of low wind speeds and overestimating the size of areas with low wind speeds near buildings (Yoshie et al. 2007; Zhang et al. 2020). This study took all possible precautions such as carefully selected the computational mesh following grid sensitivity analysis and estimated the accuracy of CFD simulation conducting a validation test to minimize the error. However, the use of a two-equation turbulence closure, i.e., the realizable $k-\varepsilon$ model in this study, tends to underestimate the wind speeds in building wake because of the $k-\varepsilon$ turbulence models cannot reproduce the vortex shedding in the building wake and consequently underestimates the TKE in the wake (Yoshie et al. 2007; Tominaga et al. 2008).

- Although many wind comfort criteria are based on the pedestrian-level mean wind speed, it is a well-known fact that wind discomfort can be caused by the infrequent occurrence of wind gust. Therefore, gust wind speed should be used for a comprehensive evaluation of pedestrian wind comfort. This study does not include the effect of wind gust for assessing pedestrian wind
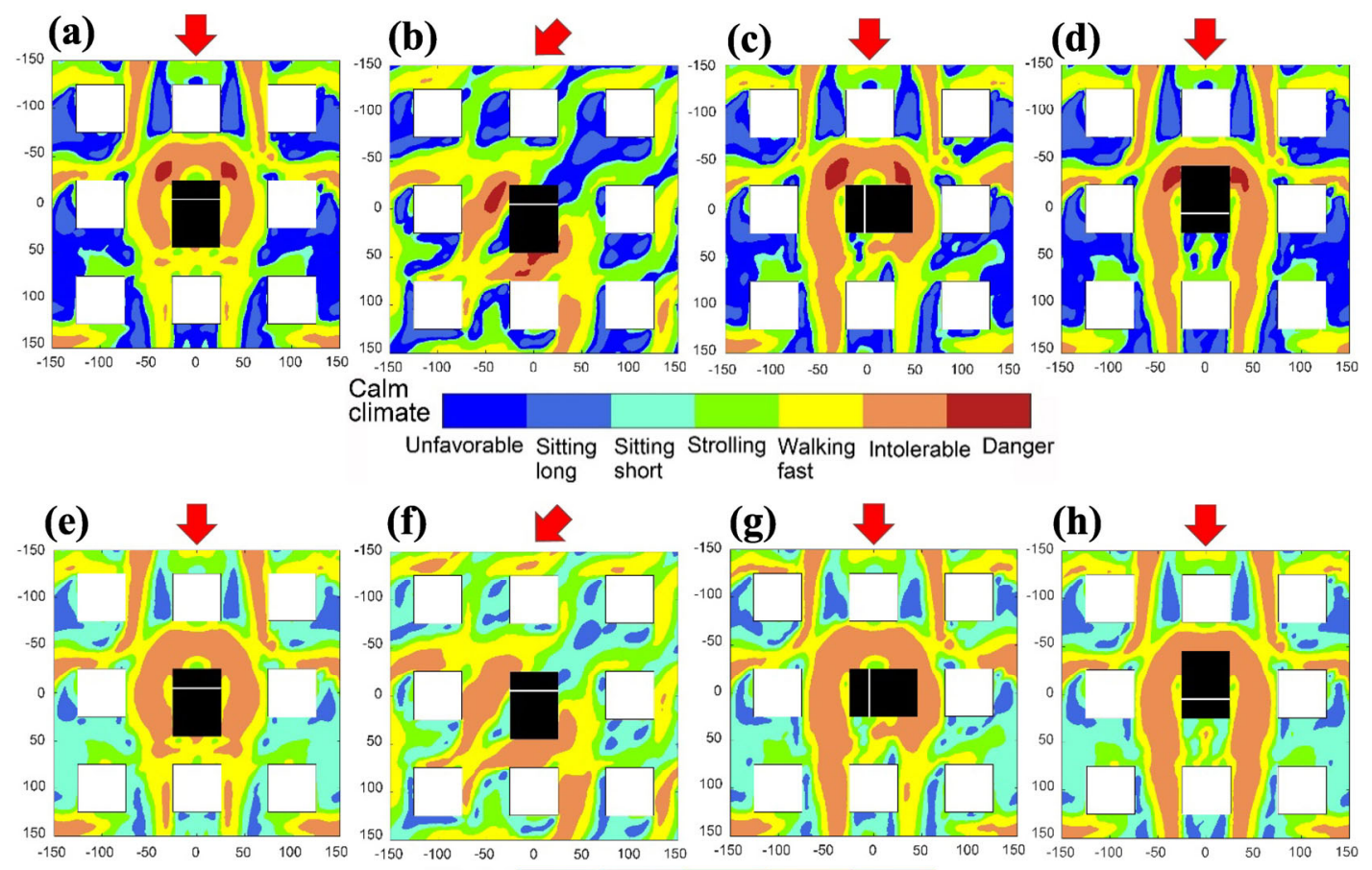

(f)

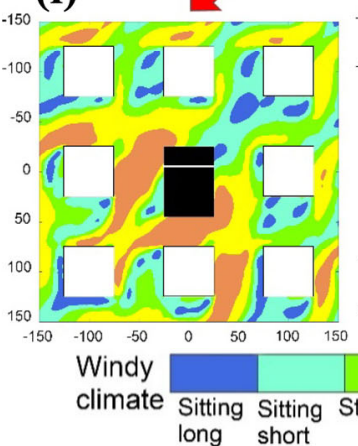

(g)

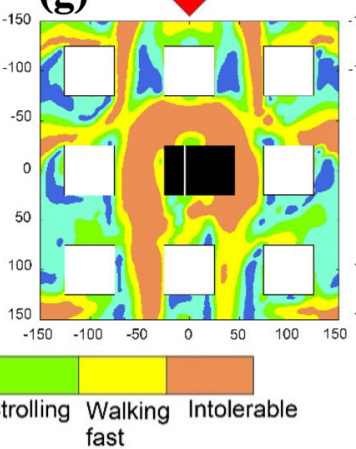

(h)

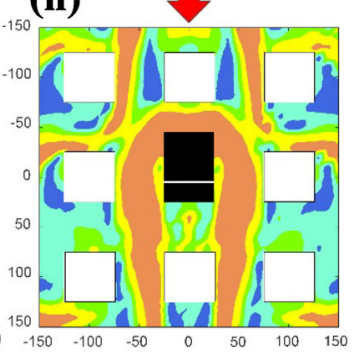

Fig. 24 Distribution of pedestrian wind comfort classes near SB-45R-SQ in: (a) $\theta=0^{\circ}$, (b) $\theta=45^{\circ}$, (c) $\theta=90^{\circ}$, (d) $\theta=180^{\circ}$ in Calm climate, and (e) $\theta=0^{\circ}$, (f) $\theta=45^{\circ}$, (g) $\theta=90^{\circ}$, (h) $\theta=180^{\circ}$ in Windy climate 
comfort because 3D RANS cannot model turbulent wind flows, and the selected wind comfort criteria for this study are based on pedestrian level mean wind speed. This shortcoming can be eliminated by employing LES for the assessment, but LES is computationally expensive for this type of study.

- The wind comfort criteria used for assessing PLWE in Calm climate have some shortcomings compared to other well-established criteria. The criteria proposed by Du et al. (2017) use different threshold wind speeds and probabilities of exceedance for different wind comfort classes. This is a noticeable difference from other criteria, which employ either a single probability of exceedance such as Lawson's criteria (Lawson 1978) or a single threshold wind velocity such as the Dutch standard for wind comfort NEN8100 (Janssen et al. 2013) to determine wind comfort classes. The use of different wind velocities and probabilities of exceedance in the criteria proposed by $\mathrm{Du}$ et al. (2017) may cause ambiguities in assigning wind comfort classes for the areas in the PLWE. In such cases, it is advisable to use the engineering judgment of the assessor in assigning a particular wind comfort class to the area of interest in the PLWE.

- The current study employs a regular building array to represent a medium-dense urban area. However, Zhang et al. (2020) have pointed out a possible influence of surrounding buildings on the PLWE near a super-tall building. Therefore, it is prudent to model various urban surroundings with buildings with different arrangements, non-uniform heights, various frontal and plan areas in future studies for assessing pedestrian wind comfort near a super-tall building in an urban area.

\section{Concluding remarks}

The current study provides a comprehensive understanding of the pedestrian wind comfort near a $400 \mathrm{~m}$ super-tall building with various configurations in an urban-like setting in Calm and Windy climates. Moreover, the findings offer valuable insights on selecting suitable configurations for a super-tall building to maintain an acceptable wind environment for pedestrians in the two climates. Some of the key findings are:

1) The construction of a $400 \mathrm{~m}$ square-shaped super-tall building in a regular urban area increases the maximum pedestrian-level wind speed by a factor of 1.53 , which is $33 \%$ less than the maximum pedestrian-level wind speed near an isolated super-tall building with similar dimensions. The increase of pedestrian-level wind speed in the regular urban area results in on average $22 \%-15 \%$ and $36 \%-29 \%$ decrease in $A_{\text {com }}$ in Calm and Windy climates, respectively.

2) The pedestrian wind comfort near a square-shaped super-tall building can be enhanced by adopting minor aerodynamic treatments such as corner modifications. Corner modifications are advantageous in swelling the areas with wind comfort in Windy climate and alleviating wind discomfort by reducing the size of areas rated as "Intolerable" and "Dangerous" in Calm and Windy climates.

3) Major aerodynamic modifications such as tapered, setbacks, and building openings do not necessarily enhance the pedestrian wind comfort compared to a square-shaped super-tall building. However, major aerodynamic modifications are advantageous in controlling the size of areas with extreme wind discomfort. For example, LIF in Calm climate prevents the formation of large areas rated as "Unfavorable", and TL-SQ in Windy climate creates smaller areas graded as "Intolerable".

4) Pedestrian wind comfort near a super-tall building strongly depends on building configurations with sharp corners, varying cross-sections, and cross-sections' orientations. Building configurations without sharp corners such as CIR or OCT ameliorate the pedestrian wind comfort while the configurations with sharp corners such as TRI and PEN hamper the quality of PLWE. Super-tall buildings with varying cross-section and orientations have complex impacts on pedestrian wind comfort, for example, SB-45R-SQ is advantageous in shrinking the areas rated as "Unfavorable" at the same time, it swells the areas labeled as "Dangerous" for pedestrians.

5) The orientation of the super-tall building is imperative in creating acceptable wind conditions for pedestrians. Buildings with the plan aspect ratio (width/depth) larger than one should be oriented its longer building axis parallel to the dominant wind direction to have larger areas with acceptable wind comfort. Tilted building should be designed with backward inclination to the dominant wind direction than with forward inclination to prevent forming large areas categorized as "Intolerable" in Windy climate.

\section{Acknowledgements}

The work described in this paper was supported by a grant from the Research Grants Council of the Hong Kong Special Administrative Region, China (Project No. 16207118) and the General Research Fund (GRF) of Hong Kong Research Grants Council (RGC) HKU 1725616.

\section{References}

AIJ (n.d.). Guidebook for CFD Predictions of Urban Wind Environment. Architectural Institute of Japan. Available at https://www.aij.or.jp/ jpn/publish/cfdguide/index_e.htm. Accessed 8 Apr 2020. 
Arens E, Ballanti D, Bennett C, Guldman S, White B (1989). Developing the San Francisco wind ordinance and its guidelines for compliance. Building and Environment, 24: 297-303.

Beranek WJ (1984). Wind environment around single buildings of rectangular shape. Heron, 29(1): 2-29.

Blocken B, Stathopoulos T, Carmeliet J (2007a). CFD simulation of the atmospheric boundary layer: wall function problems. Atmospheric Environment, 41: 238-252.

Blocken B, Carmeliet J, Stathopoulos T (2007b). CFD evaluation of wind speed conditions in passages between parallel buildingseffect of wall-function roughness modifications for the atmospheric boundary layer flow. Journal of Wind Engineering and Industrial Aerodynamics, 95: 941-962.

Blocken B, Persoon J (2009). Pedestrian wind comfort around a large football stadium in an urban environment: CFD simulation, validation and application of the new Dutch wind nuisance standard. Journal of Wind Engineering and Industrial Aerodynamics, 97: 255-270.

Blocken B, Stathopoulos T (2013). CFD simulation of pedestrian-level wind conditions around buildings: Past achievements and prospects. Journal of Wind Engineering and Industrial Aerodynamics, 121: 138-145.

Blocken B (2014). 50 years of Computational Wind Engineering: Past, present and future. Journal of Wind Engineering and Industrial Aerodynamics, 129: 69-102.

Blocken B, Stathopoulos T, van Beeck JPAJ (2016). Pedestrian-level wind conditions around buildings: Review of wind-tunnel and CFD techniques and their accuracy for wind comfort assessment. Building and Environment, 100: 50-81.

Blocken B (2018). LES over RANS in building simulation for outdoor and indoor applications: A foregone conclusion? Building Simulation, 11: 821-870.

Cebeci T, Bradshaw P (1977). Momentum Transfer in Boundary Layers. Washington, DC: Hemisphere Publishing.

Cheng V, Ng E, Chan C, Givoni B (2012). Outdoor thermal comfort study in a sub-tropical climate: a longitudinal study based in Hong Kong. International Journal of Biometeorology, 56: 43-56.

Davis PL, Rinehimer AT, Uddin M (2012). A comparison of RANSbased turbulence modeling for flow over a wall-mounted square cylinder. In: Proceedings of the 20th Annual Conference of the CFD Society of Canada, Canmore, Canada.

Du Y, Mak CM, Kwok K, Tse KT, Lee TC, et al. (2017). New criteria for assessing low wind environment at pedestrian level in Hong Kong. Building and Environment, 123: 23-36.

Durgin FH (1989). Proposed guidelines for pedestrian level wind studies for Boston-Comparison of results from 12 studies. Building and Environment, 24: 305-314.

Durgin FH (1992). Pedestrian level wind studies at the Wright brothers facility. Journal of Wind Engineering and Industrial Aerodynamics, 44: 2253-2264.

Durgin FH (1997). Pedestrian level wind criteria using the equivalent average. Journal of Wind Engineering and Industrial Aerodynamics, 66: 215-226.

Dutton R, Isyumov N (1990). Reduction of tall building motion by aerodynamic treatments. Journal of Wind Engineering and Industrial Aerodynamics, 36: 739-747.

Franke J, Hellsten A, Schlunzen KH, Carissimo B (2011). The COST 732 Best Practice Guideline for CFD simulation of flows in the urban environment: a summary. International Journal of Environment and Pollution, 44: 419-427.

Gandemer J (1978a). Aerodynamic studies of built-up areas made by C.S.T.B. at Nantes, France. Journal of Wind Engineering and Industrial Aerodynamics, 3: 227-240.

Gandemer J (1978b). Discomfort due to wind near buildings: Aerodynamic concepts. Gaithersburg, MD, USA: National Bureau of Standards.

Grimmond CSB, Oke TR (1999). Aerodynamic properties of urban areas derived from analysis of surface form. Journal of Applied Meteorology, 38: 1262-1292.

Hunt JCR, Poulton EC, Mumford JC (1976). The effects of wind on people; New criteria based on wind tunnel experiments. Building and Environment, 11: 15-28.

Irwin HPAH (1981). A simple omnidirectional sensor for wind-tunnel studies of pedestrian-level winds. Journal of Wind Engineering and Industrial Aerodynamics, 7: 219-239.

Isyumov N (1978). Studies of the pedestrian level wind environment at the boundary layer wind tunnel laboratory of the University of Western Ontario. Journal of Wind Engineering and Industrial Aerodynamics, 3: 187-200.

Jackson PS (1978). The evaluation of windy environments. Building and Environment, 13: 251-260.

Jamieson NJ, Carpenter P, Cenek PD (1992). The effect of architectural detailing on pedestrian level wind speeds. Journal of Wind Engineering and Industrial Aerodynamics, 44: 2301-2312.

Janssen WD, Blocken B, van Hooff T (2013). Pedestrian wind comfort around buildings: Comparison of wind comfort criteria based on whole-flow field data for a complex case study. Building and Environment, 59: 547-562.

Kamei I, Maruta E (1979). Study on wind environmental problems caused around buildings in Japan. Journal of Wind Engineering and Industrial Aerodynamics, 4: 307-331.

Kawai H (1998). Effect of corner modifications on aeroelastic instabilities of tall buildings. Journal of Wind Engineering and Industrial Aerodynamics, 74-76: 719-729.

Kim Y, Jun K (2010). Characteristics of aerodynamic forces and pressures on square plan buildings with height variations. Journal of Wind Engineering and Industrial Aerodynamics, 98: 449-465.

Kim YC, Tamura Y, Tanaka H, Ohtake K, Bandi EK, Yoshida A (2014). Wind-induced responses of super-tall buildings with various atypical building shapes. Journal of Wind Engineering and Industrial Aerodynamics, 133: 191-199.

Kim YC, Bandi EK, Yoshida A, Tamura Y (2015a). Response characteristics of super-tall buildings - Effects of number of sides and helical angle. Journal of Wind Engineering and Industrial Aerodynamics, 145: 252-262.

Kim YC, Tamura Y, Yoon SW (2015b). Effect of taper on fundamental aeroelastic behaviors of super-tall buildings. Wind and Structures, 20: 527-548. 
Kwok KCS (1988). Effect of building shape on wind-induced response of tall building. Journal of Wind Engineering and Industrial Aerodynamics, 28: 381-390.

Launder BE, Spalding DB (1983). The numerical computation of turbulent flows. In: Patankar SV, Pollard A, Singhal AK, Vanka SP (eds), Numerical Prediction of Flow, Heat Transfer, Turbulence and Combustion. New York: Pergamon Press. pp. 96-116.

Lawson TV (1978). The wind content of the built environment. Journal of Wind Engineering and Industrial Aerodynamics, 3: 93-105.

Lee BE, Hussain M (1979). The ground level wind environment around the Sheffield University arts tower. Journal of Wind Engineering and Industrial Aerodynamics, 4: 333-341.

Lin M, Hang J, Li Y, Luo Z, Sandberg M (2014). Quantitative ventilation assessments of idealized urban canopy layers with various urban layouts and the same building packing density. Building and Environment, 79: 152-167.

Melbourne WH (1971). Problem of wind flow at base of tall buildings. In: Proceedings of the 2nd Internatinal Conference on Wind Effects on Buildings and Structures, Tokyo, Japan.

Melbourne WH (1978a). Wind environment studies in Australia. Journal of Wind Engineering and Industrial Aerodynamics, 3: 201-214.

Melbourne WH (1978b). Criteria for environmental wind conditions. Journal of Wind Engineering and Industrial Aerodynamics, 3: 241-249.

Mochida A, Lun IYF (2008). Prediction of wind environment and thermal comfort at pedestrian level in urban area. Journal of Wind Engineering and Industrial Aerodynamics, 96: 1498-1527.

Murakami S, Uehara K, Komine H (1979). Amplification of wind speed at ground level due to construction of high-rise building in urban area. Journal of Wind Engineering and Industrial Aerodynamics, 4: 343-370.

Murakami S, Iwasa Y, Morikawa Y (1986). Study on acceptable criteria for assessing wind environment at ground level based on residents' diaries. Journal of Wind Engineering and Industrial Aerodynamics, 24: 1-18.

$\mathrm{Ng}$ E (2009). Policies and technical guidelines for urban planning of high-density cities - air ventilation assessment (AVA) of Hong Kong. Building and Environment, 44: 1478-1488.

Penwarden AD, Wisse AFE (1975). Wind environment around buildings. Her Majesty's Stationary Office, London.

Penwarden AD (1973). Acceptable wind speeds in towns. Building Science, 8: 259-267.

Ramponi R, Blocken B, de Coo LB, Janssen WD (2015). CFD simulation of outdoor ventilation of generic urban configurations with different urban densities and equal and unequal street widths. Building and Environment, 92: 152-166.

Shih TH, Liou WW, Shabbir A, Yang Z, Zhu J (1995). A new k- $€$ eddy viscosity model for high Reynolds number turbulent flows. Computers \& Fluids, 24: 227-238.

Stathopoulos T (1985). Wind environmental conditions around tall buildings with chamfered corners. Journal of Wind Engineering and Industrial Aerodynamics, 21: 71-87.

Stathopoulos T, Wu H (2004). Using computational fluid dynamics
(CFD) for pedestrian winds. In: Proceedings of Structures 2004: Building on the Past, Securing the Future.

Stathopoulos T, Wu H, Bédard C (1992). Wind environment around buildings: A knowledge-based approach. Journal of Wind Engineering and Industrial Aerodynamics, 44: 2377-2388.

Tamura Y, Tanaka H, Ohtake K, Nakai M, Kim Y (2010). Aerodynamic characteristics of tall building models with various unconventional configurations. In: Proceedings of Structures Congress 2010.

Tanaka H, Tamura Y, Ohtake K, Nakai M, Kim YC (2012). Experimental investigation of aerodynamic forces and wind pressures acting on tall buildings with various unconventional configurations. Journal of Wind Engineering and Industrial Aerodynamics, 107-108: 179-191.

Tanaka H, Tamura Y, Ohtake K, Nakai M, Kim YC, Bandi EK (2013). Aerodynamic and flow characteristics of tall buildings with various unconventional configurations. International Journal of High-Rise Buildings, 2: 213-228.

Tominaga Y, Mochida A, Shirasawa T, Yoshie R, Kataoka H, Harimoto K, Nozu T (2004). Cross comparisons of CFD results of wind environment at pedestrian level around a high-rise building and within a building complex. Journal of Asian Architecture and Building Engineering, 3: 63-70.

Tominaga Y, Mochida A, Yoshie R, Kataoka H, Nozu T, Yoshikawa M, Shirasawa T (2008). AIJ guidelines for practical applications of CFD to pedestrian wind environment around buildings. Journal of Wind Engineering and Industrial Aerodynamics, 96: 1749-1761.

Tsang CW, Kwok KCS, Hitchcock PA (2012). Wind tunnel study of pedestrian level wind environment around tall buildings: Effects of building dimensions, separation and podium. Building and Environment, 49: 167-181.

Tse KT, Hitchcock PA, Kwok KCS, Thepmongkorn S, Chan CM (2009). Economic perspectives of aerodynamic treatments of square tall buildings. Journal of Wind Engineering and Industrial Aerodynamics, 97: 455-467.

Tse KT, Weerasuriya AU, Zhang X, Li S, Kwok KCS (2017a). Pedestrian-level wind environment around isolated buildings under the influence of twisted wind flows. Journal of Wind Engineering and Industrial Aerodynamics, 162: 12-23.

Tse KT, Zhang X, Weerasuriya AU, Li SW, Kwok KCS, Mak CM, Niu J (2017b). Adopting 'lift-up' building design to improve the surrounding pedestrian-level wind environment. Building and Environment, 117: 154-165.

Uematsu Y, Yamada M (1991). Application of infrared thermography to the evaluation of pedestrian-level winds around buildings. In: Proceedings of the 1st Conference on Experimental Fluid Mechanics, Beijing, China.

Uematsu Y, Yamada M, Higashiyama H, Orimo T (1992). Effects of the corner shape of high-rise buildings on the pedestrian-level wind environment with consideration for mean and fluctuating wind speeds. Journal of Wind Engineering and Industrial Aerodynamics, 44: 2289-2300.

van Druenen T, van Hooff T, Montazeri H, Blocken B (2019). CFD evaluation of building geometry modifications to reduce pedestrianlevel wind speed. Building and Environment, 163: 106293. 
van Hooff T, Blocken B (2010). Coupled urban wind flow and indoor natural ventilation modelling on a high-resolution grid: A case study for the Amsterdam ArenA stadium. Environmental Modelling \& Software, 25: 51-65.

Wang T, Wu YY, Cheung TF, Lam KS (2001). A study of surface ozone and the relation to complex wind flow in Hong Kong. Atmospheric Environment, 35: 3203-3215.

Weerasuriya AU, Tse KT, Zhang X, Kwok KCS (2018). Integrating twisted wind profiles to Air Ventilation Assessment (AVA): The current status. Building and Environment, 135: 297-307.

Willemsen E, Wisse JA (2007). Design for wind comfort in The Netherlands: Procedures, criteria and open research issues. Journal of Wind Engineering and Industrial Aerodynamics, 95: 1541-1550.

Wong MS, Nichol JE, To PH, Wang J (2010). A simple method for designation of urban ventilation corridors and its application to urban heat island analysis. Building and Environment, 45: 1880-1889.

$\mathrm{Wu} \mathrm{H}$, Stathopoulos T (1993). Wind-tunnel techniques for assessment of pedestrian-level winds. Journal of Engineering Mechanics, 119: 1920-1936.

Wu H (1994). Pedestrian-level wind environment around buildings. PhD Thesis, Concordia University, Canada.

Xu X, Yang Q, Yoshida A, Tamura Y (2017). Characteristics of pedestrian-level wind around super-tall buildings with various configurations. Journal of Wind Engineering and Industrial Aerodynamics, 166: 61-73.
Yim SHL, Fung JCH, Lau AKH, Kot SC (2009). Air ventilation impacts of the "wall effect" resulting from the alignment of high-rise buildings. Atmospheric Environment, 43: 4982-4994.

Yip C, Chang WL, Yeung KH, Yu IT (2007). Possible meteorological influence on the severe acute respiratory syndrome (SARS) community outbreak at Amoy Gardens, Hong Kong. Journal of environmental health, 70(3), 39-47.

Yoshie R, Mochida A, Tominaga Y, Kataoka H, Harimoto K, Nozu T, Shirasawa $\mathrm{T}$ (2007). Cooperative project for CFD prediction of pedestrian wind environment in the Architectural Institute of Japan. Journal of Wind Engineering and Industrial Aerodynamics, 95: 1551-1578.

Zhang X, Tse KT, Weerasuriya AU, Li SW, Kwok KCS, et al. (2017). Evaluation of pedestrian wind comfort near 'lift-up' buildings with different aspect ratios and central core modifications. Building and Environment, 124: 245-257.

Zhang X, Tse KT, Weerasuriya AU, Kwok KCS, Niu J, Lin Z, Mak CM (2018). Pedestrian-level wind conditions in the space underneath lift-up buildings. Journal of Wind Engineering and Industrial Aerodynamics, 179: 58-69.

Zhang X, Weerasuriya AU, Lu B, Tse KT, Liu CH, Tamura Y (2020). Pedestrian-level wind environment near a super-tall building with unconventional configurations in a regular urban area. Building Simulation, 13: 439-456. 